\title{
Interplay between the Ubiquitin Proteasome System and Mitochondria for Protein Homeostasis
}

\author{
Mafalda Escobar-Henriques ${ }^{1 *}$, Selver Altin ${ }^{1}$ and Fabian den Brave ${ }^{2}$
}

\author{
${ }^{1}$ Institute for Genetics, Cologne Excellence Cluster on Cellular Stress Responses in Aging- \\ Associated Diseases (CECAD), Center for Molecular Medicine Cologne (CMMC), University \\ of Cologne, Cologne, Germany. \\ ${ }^{2}$ Department of Molecular Cell Biology, Max Planck Institute of Biochemistry, Martinsried, \\ Germany. \\ *Correspondence: mafalda.escobar@uni-koeln.de
}

https://doi.org/10.21775/cimb.035.035

\begin{abstract}
Eukaryotic cells are subdivided into membranebound compartments specialized in different cellular functions and requiring dedicated sets of proteins. Although cells developed compartmentspecific mechanisms for protein quality control, chaperones and ubiquitin are generally required for maintaining cellular proteostasis. Proteotoxic stress is signalled from one compartment into another to adjust the cellular stress response. Moreover, transport of misfolded proteins between different compartments can buffer local defects in protein quality control. Mitochondria are special organelles in that they possess an own expression, folding and proteolytic machinery, of bacterial origin, which do not have ubiquitin. Nevertheless, the importance of extensive crosstalk between mitochondria and other subcellular compartments is increasingly clear. Here, we will present local quality control mechanisms and discuss how cellular proteostasis is affected by the interplay between mitochondria and the ubiquitin proteasome system.
\end{abstract}

\section{Introduction}

In order to fulfil their biological function, proteins must fold into their native three-dimensional structures and organelles need to function properly. The factors controlling protein homeostasis processes are collectively termed the proteostasis network (Klaips et al., 2018). In sum, cells must ensure either proper protein folding or -if this failsundertake efficient elimination of malfunctioning proteins or damaged organelles. A prominent role in proteostasis is ensured by ATP-dependent cellular machineries dedicated to proper protein folding, called chaperones (Hartl et al., 2011). In turn, the central proteolytic components of this network are the ubiquitin proteasome system (UPS), a soluble machinery, and the lysosomes, organelles that enclose peptidases with a powerful and non-specific lytic capacity (Bard et al., 2018). Consequently, the UPS is the main proteolytic pathway of the cell for cytosolic substrates, being the lysosomes generally responsible for the clearance of membrane proteins, entire organelles and large protein aggregates (Kerscher et al., 2006; Amm et al., 2014). Both processes 
rely on the ear-marking of the desired protein with ubiquitin. In addition, autophagy requires the ubiquitin-like proteins or Atg8(yeast)/LC3(mammals).

Organelles, despite being functional units with dedicated roles, must respond to their cellular environment. Mitochondria - the cellular energy powerhouse - are special semi-autonomous organelles, which evolved through a symbiotic event of alpha-proteobacterium at the origin of a eukaryotic cell (Zimorski et al., 2014). Mitochondria possess an own DNA and the machineries allowing its replication, transcription and translation, originating from their bacterial ancestors, thus resembling the ones from free living prokaryotes (Falkenberg et al., 2007; D'Souza and Minczuk, 2018). During evolution of this endosymbiotic process, most of the mitochondrial genetic information was transferred to the nucleus. This means that most proteins located at mitochondria need to be imported from the cytoplasm, rendering mitochondrial quality control processes fundamentally important for the biogenesis of this essential organelle (Pfanner et al., 2019). Therefore, the presence at mitochondria of specific chaperones and proteases is not surprising. As mentioned, these are closely homologous to their bacterial relatives and make up for local protein quality control (Voos et al., 2016). Perhaps for this reason, it was long assumed that mitochondrial proteostasis was ubiquitin-independent. Instead, it is now clear that mitochondrial stress is also engaging cytosolic and lysosomal proteostasis networks, including ubiquitin and the UPS but also Atg8/LC3 and the lysosomes (Germain, 2008; Escobar-Henriques and Langer, 2014; Topf et al., 2016; Braun and Westermann, 2017; D'Amico et al., 2017). The most prominent example is certainly the mitophagy process, where damaged mitochondria are selectively degraded (McWilliams and Muqit, 2017). Reciprocally, mitochondria also sense and regulate external stress, clearly impacting on cellular homeostasis and longevity and certainly relevant for neurodegeneration (Chung et al., 2018; Guaragnella et al., 2018; Ruan et al., 2018).

In this review, we describe novel insights on how mitochondria crosstalk and bi-directionally cooperate with their cellular environment to deal with proteotoxic stress (see Fig. 12.1). After a general overview on quality control - cytosolic and mitochondrial - we then describe emerging

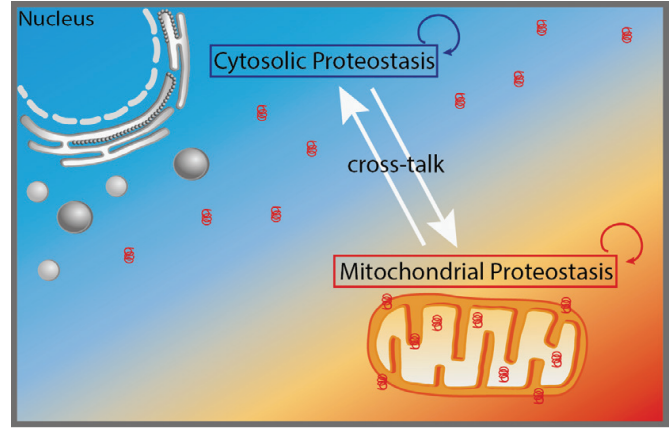

Figure 12.1 Crosstalk of cytosolic and mitochondrial proteostasis. Protein aggregates or malfunctional proteins activate different proteolytic pathways for their clearance. Mitochondria as well as the cytosol harbour their own proteolytic machineries providing clearance of damaged proteins. Nevertheless, an extensive interplay between mitochondria and their environment is key to maintain cellular homeostasis.

cross-functional concepts. First, we focus on the role of mitochondria in coping with excessive cytosolic proteostasis. These findings illustrate the proteolytic power of mitochondria, which does not depend on ubiquitin. Second, we describe several cytosolic and ubiquitin-dependent pathways engaging on mitochondria. We present integrated cellular responses, requiring ubiquitin and the proteasome or the autophagic marker LC3 and lysosomes, which contribute to alleviate mitochondrial stress. Finally, we present the dual role of the peptidyl-tRNA hydrolase Vms1 (yeast)/ANKZF1 (mammals) in ribosomal quality control and mitochondrial proteostasis, being both processes regulated by ubiquitin.

\section{Principles of protein quality control - cytosolic and mitochondrial}

Aberrant folding or unfolding does not only compromise the affected protein but is also accompanied with a great risk of disrupting the functionality of other proteins, by undergoing nonspecific protein-protein interactions. Especially metastable proteins with disordered regions (up to $30 \%$ of the mammalian proteome) are prone to undergo unwanted interactions and form toxic protein aggregates, which are associated with 
neurodegenerative diseases (Dunker et al., 2008). This underlines the broad importance of proteome surveillance. In addition, the vast majority of proteins are synthesized by cytosolic ribosomes, followed by post- or co-translational transport of proteins to their final destination (Dudek et al., 2013). Thus, the cytosolic quality control machineries are essential for the integrity of the entire cellular proteome.

\section{Quality control components in the cytoplasm}

\section{Protein folding}

Chaperones are central players in protein quality control, which support other proteins in acquiring their functional conformation, without usually being present in the final structure (Hartl, 1996). Unfolded proteins expose hydrophobic residues, normally buried inside their three-dimensional structure, being such non-native regions recognized by chaperones. Chaperones promote folding by ATP dependent cycles of binding and release of their substrate proteins, till they reach their native state. Thus, by assisting in protein folding, chaperones prevent unspecific interactions and protein aggregation and refold stress-denatured proteins. However, if encountering terminally misfolded proteins, chaperones also cooperate with proteolytic machineries in their degradation (Tyedmers et al., 2010; Balchin et al., 2016).

\section{Hsp70 chaperones}

Hsp70 chaperones and their co-factors constitute major components for protein quality control (Kityk et al., 2015). Hsp70 binds to substrates in an open, ATP bound conformation. The substratebinding pocket is closed on ATP hydrolysis and release of ADP results in substrate release. In addition to refolding soluble proteins, Hsp70 supports protein import into cellular compartments such as the endoplasmic reticulum and mitochondria, where the proteins have to pass membranes in an unfolded state, through an import channel (Craig, 2018). Moreover, Hsp70 support protein degradation machineries requiring soluble and at least partially unfolded proteins, like the $26 \mathrm{~S}$ proteasome (Fernández-Fernández et al., 2017). The binding of Hsp70 shields hydrophobic regions in non-native proteins, thereby preventing non-specific interactions, until proteins reach their native state and/or final destination.

The intrinsic activity of Hsp70 alone is low and therefore folding requires the help of additional factors. On the one hand, efficient Hsp70 function requires one of several structurally unrelated nucleotide exchange factors (NEFs), which promote the exchange between ADP and ATP. On the other hand, ATPase activity is stimulated by Hsp40 chaperones, also called J-proteins, which bind the substrates and deliver them to Hsp70, thus avoiding their aggregation. Therefore, substrate specificity of $\mathrm{Hsp} 70$ is mainly determined by Hsp40 chaperones (Kampinga and Craig, 2010). These often contain substrate-binding domains themselves and mediate the transfer of substrates to Hsp70, depending on their J-domain. In addition, several specialized Hsp40s lack a substrate-binding domain but localize Hsp70 within the cell to the vicinity of certain substrates. For instance, the Hsp40 Zuol targets cytosolic Hsp70 to the ribosomal exit tunnel to aid in folding of nascent proteins (Yan et al., 1998; Gautschi et al., 2001). In sum, Hsp40 chaperones, in conjunction with NEFs, are responsible for the versatile functions exerted by the Hsp70 system (Fig. 12.2).

\section{Protein ubiquitination and turnover by the UPS}

When proteins cannot reach their native conformation, due to mutations or exogenous stresses, they might interfere with the function or folding of other proteins, and thus have to be separated from the rest of the proteome. This can be achieved by sequestration into inclusions or through proteolytic breakdown (Fig. 12.2). The main machinery degrading soluble proteins, in the cytosol and in the nucleus, is the ubiquitin proteasome system (UPS) (Kerscher et al., 2006; Amm et al., 2014). Turnover of proteins generally requires them being tagged with ubiquitin, a highly conserved small protein of 76 aa. It occurs by the covalent attachment of ubiquitin to lysine residues in target proteins (termed ubiquitination). Substrate ubiquitination is mediated by an enzymatic cascade, involving an ubiquitin-activating enzyme (E1), ubiquitin-conjugating enzymes (E2), and ubiquitin protein ligases (E3). Specificity towards individual 


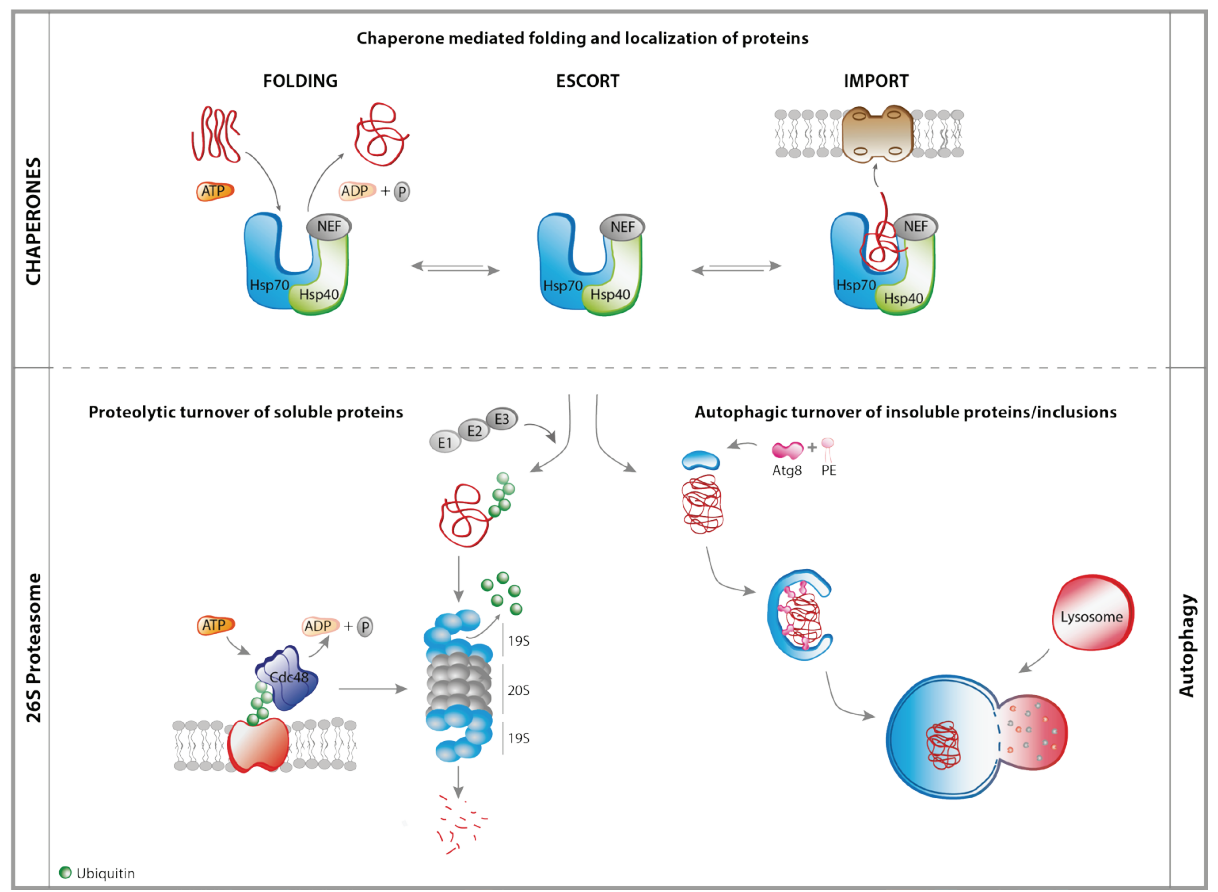

Figure 12.2 Chaperones, ubiquitin-proteasome system and autophagy. Different layers of quality control machineries maintain cellular protein homeostasis. As a first layer, the chaperone Hsp70 as well as its cofactors (Hsp40) and nucleotide exchange factors (NEF) mediate protein folding, escort target proteins to their destination and support import of nascent polypeptide chains into organelles. The ubiquitin proteasome system (UPS, 26S Proteasome, consisting of its 19S regulatory particle and the 20 S proteolytic core) represents the second layer of protein quality control. Substrate proteins targeted with the small modifier ubiquitin (E1, E2 and E3 enzymes mediate covalent attachment of ubiquitin to the substrate) are degraded by the 26S proteasome, whereby ubiquitin itself is recycled. The accessibility of defective proteins to the $26 \mathrm{~S}$ proteasome is supported by the AAA-ATPase Cdc48, which extracts ubiquitinated membrane proteins. As a third layer, protein aggregates/inclusion, organelles or pathogens are targeted to autophagy. This requires the engulfment by an autophagosome, which expands around the substrate by the lipidation of the ubiquitin-like modifier Atg8 with phosphatidylethanolamine (PE). Subsequently, the autophagosome fuses with a cellular lysosome, where final degradation occurs. (NEF, nucleotide exchange factor; ATP, adenosine triphosphate; ADP, adenosine diphosphate; P, phosphate).

substrates, or target recognition, is mostly mediated by the E3 ligase enzymes. Ubiquitination can either result in the attachment of single ubiquitin moieties (mono-ubiquitination), or chains build on lysine residues within ubiquitin itself (poly-ubiquitination). The seven lysine residues of ubiquitin allow the formation of different types of ubiquitin-chains. Often, these serve as targets for different ubiquitinlinkage specific binding proteins, thereby dictating the downstream consequences of ubiquitination. Finally, ubiquitin is a reversible process, being cleaved by ubiquitin-specific peptidases called deubiquitinases (Komander and Rape, 2012). Ubiquitin chains formed via lysine 48 of ubiquitin are the canonical signal targeting proteins for degradation by the $26 \mathrm{~S}$ proteasome. This protease complex degrades proteins into short peptides by multiple proteolytic activities within its barrel shaped $20 \mathrm{~S}$ core particle, being its $19 \mathrm{~S}$ particle responsible for regulatory functions (Fig. 12.2).

\section{Role of Cdc48/p97NCP}

The $26 \mathrm{~S}$ proteasome is only able to degrade soluble proteins. Thus, substrates bound to larger structures, such as protein complexes, or embedded into membranes, need to be extracted before degradation, with the help of accessory factors (Fig. 12.2). The main component of the UPS exerting this function 
is the ATPase and ubiquitin-dedicated chaperone Cdc48 (p97/VCP in mammals). Cdc48 segregates proteins by an ATPase driven mechanism, thereby allowing proteolysis by the $26 \mathrm{~S}$ proteasome. Cdc48 assembles with several ubiquitin-binding co-factors, which assist it in substrate recognition. Moreover, Cdc48 also directly binds ubiquitinligases and deubiquitinating proteins, thus acting as a general hub in ubiquitin related processes (van den Boom and Meyer, 2018).

\section{Autophagy}

In contrast to soluble proteins, larger structures are refractory to proteasomal turnover. Interestingly, proteasomes can be much smaller in size than protein aggregates. In fact, cryo-EM structures identified entire proteasomes incorporated into the structure of a sub-set of large protein aggregates (Guo et al., 2018). While being consistent with biomedical data suggesting up to $50 \%$ proteasome entanglement in neurons, these structures also possibly explain reduced proteasomal activity in neurodegeneration (Pontano Vaites and Harper, 2018).

Protein aggregates can be targeted for degradation inside the lysosomes, organelles that are called vacuoles in yeast and plants (Khaminets et al., 2016). In this process, termed macroautophagy (hereafter autophagy), substrates are engulfed by double-membrane bound autophagosomes, which subsequently fuse with the vacuole/lysosome (Fig. 12.2). Vacuoles are acidic compartments containing promiscuous proteolytic enzymes that then deconstruct the engulfed substrates. Similarly to the UPS substrates, which are ear-marked by ubiquitin, the autophagosome membrane is ear-marked by the small ubiquitin-like modifier Atg8 (LC3 in mammals). Atg8 is a cytosolic protein that gets covalently conjugated to the lipid phosphatidylethanolamine at the autophagosomal membrane, on induction of autophagy. In addition to aggregated proteins, a broad range of substrates can be targeted for turnover by autophagy, including entire organelles or pathogens. These pathways of selective autophagy utilize specific autophagy receptors, which characteristically have a dual organization, consisting of a substrate recognition domain and an Atg8 interacting motif. Therefore, autophagy receptors promote the engulfment of their substrates by bridging the autophagosomal membrane to the target substrates. For example, the selective turnover of mitochondria, or mitophagy, depends on the ubiquitination of a myriad of substrates at the mitochondrial outer membrane, which engage several autophagy receptors like Optineurin, NDP52 and p62 (Geisler et al., 2010; Narendra et al., 2010; Lazarou et al., 2015; Khaminets et al., 2016; McWilliams and Muqit, 2017). Moreover, similar to misfolded soluble substrates, modification by ubiquitin of protein aggregates targets them for degradation by selective autophagy, utilizing specific receptors containing ubiquitin-binding domains. For example, Hsp42 dependent aggregate formation has been shown to be required for the turnover of defective proteasome subunits by autophagy (Marshall et al., 2016). This common feature of the UPS and selective autophagy ensures efficient degradation of aberrant proteins once they have been tagged for degradation (Lu et al., 2017).

\section{Protein inclusions}

When efficient degradation fails, especially during acute stress or when the proteostasis network is perturbed, proteins are sequestered into inclusions, thereby minimizing their reactive surface compared to soluble proteins (Miller et al., 2015; Sontag et al., 2017). Such inclusions are often transient structures, which can either be resolved by disaggregating chaperones, or instead be degraded by selective autophagy, in case they persist in the cytoplasm.

\section{General features of mitochondria}

\section{Mitochondrial functions}

Mitochondria are central organelles of all eukaryotic cells, functioning as energy-converting powerhouses, metabolic factories and signalling centres (McBride et al., 2006; Nunnari and Suomalainen, 2012). They are required for oxidative phosphorylation (OXPHOS), thus being known as the ATP powerhouse. In addition, mitochondria are key for many metabolic processes, like the synthesis of phospholipids (Silva Ramos et al., 2016; Tatsuta and Langer, 2017). Moreover, the assembly of ironsulfur-clusters (essential enzymatic cofactors) starts within mitochondria, reason why these organelles are essential for cellular viability (Braymer and Lill, 2017; Cardenas-Rodriguez et al., 2018). Finally, mitochondria are active components of many 
signalling pathways, such as programmed cell death, ageing, cellular differentiation and organism development (Green et al., 2014; Kauppila et al., 2017; Noguchi and Kasahara, 2018; Pallafacchina et al., 2018; Paupe and Prudent, 2018; Zhang et al., 2018).

\section{Sub-compartmentalization of mitochondria}

Mitochondria are bound by two separate membranes, the outer mitochondrial membrane and the inner mitochondrial membrane (Jakobs and Wurm, 2014; Schorr and van der Laan, 2018). The two compartments bound by these membranes are called intermembrane space and matrix. The inner membrane forms large invaginations, called cristae, harbouring the respiratory OXPHOS chain complexes. Moreover, the part of the inner membrane that lines parallel to the outer membrane is called inner boundary membrane. Finally, cristae and inner boundary membrane are connected at cristae junctions, and the outer membrane and the inner boundary membrane make close contacts, termed contact sites. Due to their high biosynthetic demands, mitochondria are extremely rich in proteins, many of which are assembled into large complexes, often embedded into the mitochondrial inner and outer membrane, respectively. Given that $99 \%$ of mitochondrial proteins are nuclearencoded, most of the organellar proteome needs to be post-translationally imported into the respective sub-compartment within mitochondria (Harbauer et al., 2014).

\section{Import of mitochondrial proteins}

Proteins targeted to mitochondria are mainly imported via two channels spanning both mitochondrial membranes, called TOM (translocase of the outer membrane) and TIMs (translocases of the inner membrane) (Wasilewski et al., 2017; Wiedemann and Pfanner, 2017; Pfanner et al., 2019). Together with their interaction partners, these two channels allow directing each protein to their final subcellular destination. Once inside mitochondria, imported proteins must assemble with those encoded by the mitochondrial DNA, which in humans are 13. Interestingly, translation of nuclear-encoded and mitochondrial-encoded OXPHOS components coordinately adapt to metabolic conditions stimulating respiratory growth
(Couvillion et al., 2016). Moreover, this response was shown to be unidirectionally controlled by cytosolic translation components.

\section{Mitochondrial protein quality control}

Owing to the dimensions of the protein transport pores, proteins cross the membranes in an unfolded state. In addition, the unfolded import-competent state must be protected from non-native interactions. Therefore, chaperones - ensuring proper folding and assembly into active proteins - but also proteases -allowing to eliminate faulty polypeptides- are of extreme importance for mitochondrial protein quality control (Rugarli and Langer, 2012; Voos, 2013; Voos et al., 2016) (Fig. 12.3). In addition, once proteins have reached their destination, compartment-specific mechanisms of protein quality control locally protect the proteome. Upon mitochondrial stress, several proteostasis networks have been nicely shown to operate at damaged mitochondria, for example to protect cells from death signals (D'Amico et al., 2017; Priesnitz and Becker, 2018).

\section{Chaperones guiding mitochondrial proteins}

To support efficient import of proteins targeted to mitochondria, these are kept in the cytoplasm in an unfolded state by the cytosolic Hsp70 and Hsp90 machineries (Deshaies et al., 1988; Young et al., 2003; Craig, 2018). In turn, mitochondrial Hsp70 (mtHsp70) - residing at the matrix site of the TIM complex - is crucial for the import and subsequent folding of proteins into mitochondria (Kang et al., 1990; Liu et al., 2001; Schulz et al., 2015). Protein folding inside the mitochondrial matrix largely also depends on the Hsp60-Hsp10 chaperonin, a member of the GroEL family of bacterial chaperones (Cheng et al., 1989; Reading et al., 1989). Importantly, the Hsp70 and Hsp60 systems are not only required for the folding of newly imported proteins, but also support refolding and prevent aggregation of unfolded proteins, which might occur upon proteotoxic stress (Kubo et al., 1999; Bender et al., 2011). Under conditions of severe protein folding stress, as for example acute heat stress, the abundance of unfolded proteins exceeds the capacity of mitochondrial chaperones to maintain these in a soluble state, resulting in protein aggregation. Such aggregates can be resolved 

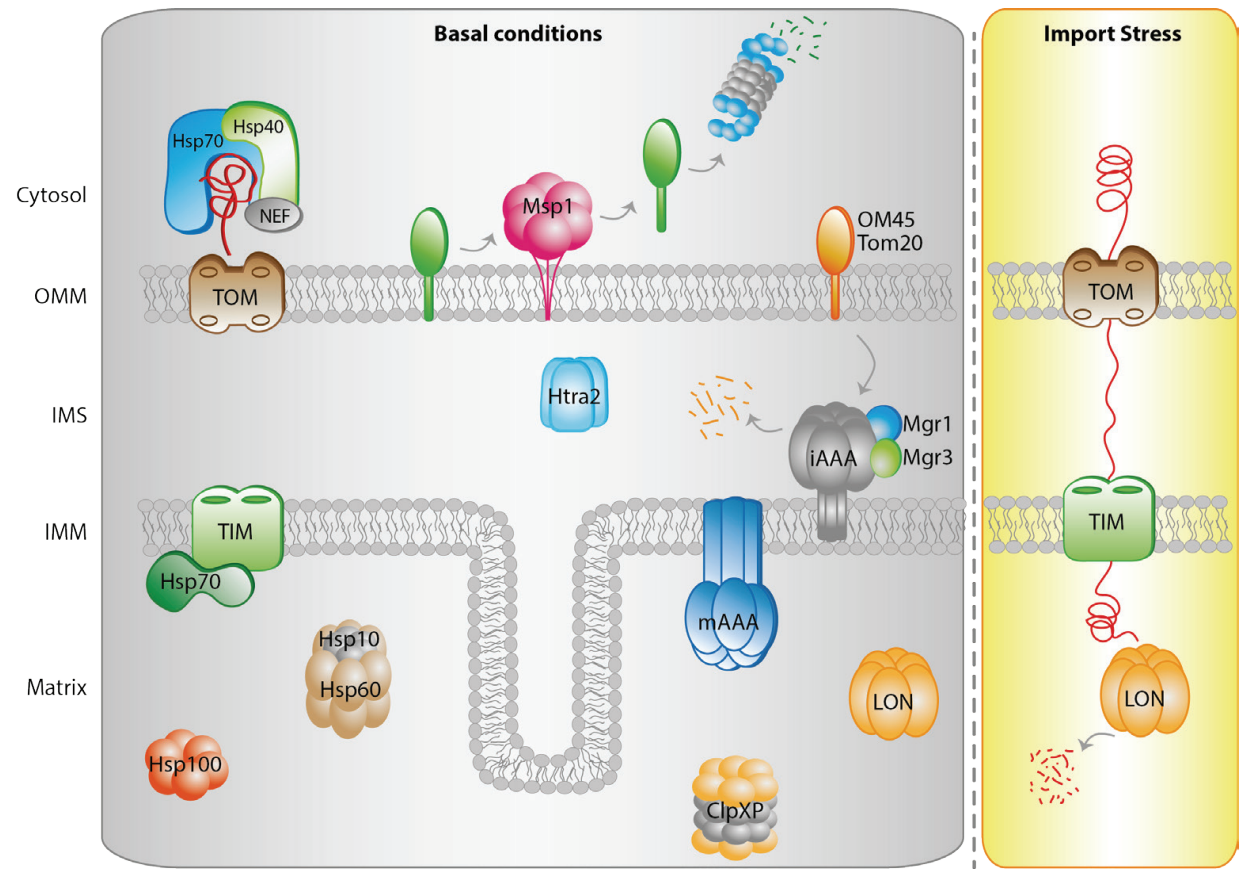

Figure 12.3 Mitochondrial quality control systems. For each individual compartment, mitochondria possess their own quality control proteins required for maintenance of the mitochondrial proteome. Within the matrix, mitochondrial Hsp70 and its cofactors (Hsp10 Hsp60, Hsp100) maintain proper protein folding after import. Turnover of misfolded proteins is regulated via the proteases LON and CIpXP. Proteolytic turnover of inner membrane proteins is mediated by $m-A A A$ at the matrix side and i-AAA on the intermembrane side. The i-AAA protease maintains also proteolytic control of outer membrane proteins like Om45 and Tom20. The protease Htra2 maintains proteolysis of misfolded and damaged proteins in the intermembrane space. At the outer membrane, the AAA-ATPase Msp1 mediates segregation of outer membrane proteins to the cytosol, which results in subsequent proteasomal turnover. Polypeptides are imported via the TOM (translocase of the outer membrane) and TIM (translocase of the inner membrane) channels. On import stress, polypeptides reaching the matrix are degraded by the Lon protease.

by mitochondrial Hsp100 chaperones, which are required for efficient recovery from acute heat stress (Schmitt et al., 1996) (Fig. 12.3).

\section{Mitochondrial proteolytic machinery}

Incorrect complex assembly or mis-targeting of membrane spanning proteins is especially prone to result in the accumulation of non-native proteins, which can undergo non-specific interactions, potentially detrimental for the cell. To remove misfolded proteins, mitochondria are equipped with a diversified set of proteases (Hamon et al., 2015; Quirós et al., 2015) (Fig. 12.3). The substrates targeted by mitochondrial proteases mainly depend on their sub-mitochondrial localization and structural properties. In general, mitochondria have ATP-dependent and independent proteases in all its sub-compartments. The first belong to the AAA+ superfamily, characterized by their oligomerization into a beta-barrel structure, enclosing a chamber with ATP-dependent pulling activity. In addition to the complete turnover of their substrates, mitochondrial proteases are also required to process and thus mature pre-proteins, for example by removing the mitochondrial targeting sequence.

The main protease degrading misfolded proteins in the mitochondrial matrix is Pim1/LON (Wagner et al., 1994). In addition, the matrix protease ClpXP has been implicated in degradation of misfolded proteins, but its function is not yet well understood (Haynes et al., 2007). Interestingly, a role of LonP1 and ClpP in regulating heteroplasmy was suggested (Latorre-Pellicer et 
al., 2016). Indeed, human mitochondrial DNA shows extensive sequence variability, suggested to impact on mitochondrial proteostasis, dependent on LonP1 and ClpP. These findings have clinical implications, in what regards mitochondrial replacement therapies, which should be considered when choosing the mitochondrial DNA donor (Latorre-Pellicer et al., 2016).

The mitochondrial inner membrane harbours two AAA proteases, which are anchored to the inner membrane by transmembrane domains (Gerdes et al., 2012; Rugarli and Langer, 2012; Levytskyy et al., 2017; Patron et al., 2018). The m-AAA protease exposes its catalytic domain to the matrix, while the catalytic domain of the i-AAA protease faces the intermembrane space. These proteases degrade misfolded proteins of the inner membrane, being their substrate specificity mainly depending on the topology of the respective substrates (Leonhard et al., 2000; Almajan et al., 2012; Stiburek et al., 2012; Anand et al., 2014; Kondadi et al., 2014; König et al., 2016; Wai et al., 2016; Wang et al., 2016; Pareek et al., 2018; Sprenger et al., 2019). In the inner mitochondrial membrane space, misfolded and damaged proteins are degraded by the proteases Omi/HtrA2 and Atp23 (Osman et al., 2007; Clausen et al., 2011). At the outer membrane, proteins are surveilled by mitochondrial and cytoplasmic quality control machineries in parallel, as discussed later.

\section{The unfolded protein response - UPR}

Mitochondrial stress inhibits mitochondrial translation, but also impacts on nuclear expression. This was termed unfolded protein response (UPR) and depends on the transcription factor ATFS-1 (Nargund et al., 2012; Jovaisaite and Auwerx, 2015; Münch and Harper, 2016; Higuchi-Sanabria et al., 2018; Shpilka and Haynes, 2018). In intact mitochondria, ATFS-1 is imported into the matrix and degraded by the protease LON. However, upon import inhibition, ATFS- 1 is diverted from the mitochondria to the nucleus. There, it up-regulates critical detoxifying genes, encoding proteins ensuring proper translation, folding and turnover at mitochondria, thus restoring mitochondrial homeostasis.

\section{Mitochondrial roles in quality control of cytosolic components}

Non-native proteins are a general threat for the cellular proteome and their spatial sequestration - into aggregates, inclusions or organelles - is a common strategy to limit such effects (Sontag et al., 2017). Moreover, misfolded proteins are transported between organelles, as it has been shown for terminally misfolded cytosolic proteins, which are transported into the nucleus for degradation (Park et al., 2013). Interestingly, novel roles of mitochondria in coping with cytosolic or cytosolic-exposed proteins have recently emerged.

\section{Mitochondrial contributions to mitigate aggregation toxicity}

\section{Asymmetric inheritance of protein aggregates}

It is known that protein aggregates that cannot be efficiently cleared by proteolytic systems are asymmetrically inherited during cell divisions, thereby ensuring that one cell deriving from such a division is free of damaged aggregated proteins (Aguilaniu et al., 2003; Shcheprova et al., 2008; Clay et al., 2014; Coelho et al., 2014; Hill et al., 2017; Saarikangas et al., 2017). Interestingly, an active role of mitochondria in restricting the mobility and thus inheritance of protein aggregates residing in the cytosol has been identified (Zhou et al., 2014). In addition, proteins aggregated inside the matrix were sequestered into specific deposits that were also retained in the mother cell (Bruderek et al., 2018). Finally, asymmetric inheritance depended on mitochondrial size and actively engaged the motor components involved in mitochondrial transport (Böckler et al., 2017). Consistent with a cellular mechanism providing for rejuvenated daughter cells, a filtering process that prevented feeble mitochondria from being inherited had equally been shown (Higuchi et al., 2013; Nyström, 2013). In contrast, however, under conditions of mild heat stress these damage-retention quality control mechanisms were inhibited. Instead, inheritance of toxic components to the daughter cell was promoted, which consequently increased longevity of the mother cell (Baldi et al., 2017). 
Import and turnover of cytosolic proteins in mitochondria

Recently, it has been observed that mitochondria can also function as a place to dispose misfolded cytosolic proteins under stress conditions. As previously mentioned, initially it had been observed that cytosolic protein aggregates are tethered to mitochondria, which facilitates asymmetric inheritance, keeping daughter cells free of the damaged proteins (Zhou et al., 2014). Consistently, purification of such aggregates revealed a physical interaction with the mitochondrial import pore (Ruan et al., 2017). Moreover, it was observed that the clearance of cytosolic aggregates was supported by import of cytosolic proteins into the mitochondrial matrix, where these proteins were handled by the Lon mitochondrial protease Pim1 (Ruan et al., 2017). The mitochondrial import and clearance of cytosolic proteins was in particular observed on acute heat shock and inhibition of cytosolic Hsp70, suggesting that this pathway functions to buffer extensive cytosolic proteotoxic stress (Ruan et al., 2017). The presence of ubiquitinated proteins inside mitochondria was suggested, which could perhaps result from similar surveillances principles (Lehmann et al., 2016). However, this does not necessarily imply a functional role of ubiquitin inside mitochondria. Import of cytosolic aggregated proteins required the disaggregase Hsp104, probably through generating soluble proteins for mitochondrial import. Surprisingly, this process was independent of cytosolic Hsp70, which usually cooperates with Hsp104 (Ruan et al., 2017). In conclusion, borrowing mitochondrial proteolytic capacity seems to have beneficial effects for stress-release of cytosolic protein load. Nevertheless, it remains an open question to which quantitative extend mitochondrial import of cytosolic proteins contributes to cytosolic proteostasis. In addition, it is still unclear if and how the import of aberrant proteins affects mitochondrial proteostasis and which mechanisms might protect mitochondria. For example, acute heat stress will also affect mitochondrial proteins and the additional uptake of non-native cytosolic proteins can be expected to pose a major challenge for the mitochondrial proteostasis network.

\section{Turnover of cytosolic-exposed proteins by mitochondrial proteases}

Transmembrane proteins residing at the outer membrane of mitochondria can, in principle, be degraded by outer membrane-embedded proteases, or be subject to membrane extraction to the cytoplasm or to mitochondria, for turnover. Interestingly, recent studies revealed a role of the i-AAA protease, or Yme1, for turnover of two outer membrane anchored proteins. Indeed, proteolysis of Tom 22 and Om45 was independent of the proteasome pathway but instead depended on Yme1 (Wu et al., 2018). In addition, proteolysis required substrate dislocation by Yme1, after recognition of their inner-membrane-space domains by the Mgr1/Mgr3 complex. Mgr1/Mgr3 interact with Yme1, thus enhancing its catalytic activity (Dunn et al., 2008). These findings show a cross-membrane mechanism for proteolytic control at mitochondria.

\section{Quality control of mitochondrial proteins in the cytoplasm}

Defects in mitochondrial targeting and import of proteins result in mis-localization of mitochondrial precursor proteins to the cytosol. Multiple concerted responses operating at the mitochondrial surface are now shown, allowing these proteins to be degraded in the cytosol by the UPS.

\section{Rescue of mitochondrial import overload by cytosolic machineries}

The import machinery at the outer membrane has an upfront role in determining mitochondrial biogenesis. Indeed, it is now clear that the import process is highly regulated, both under physiological and pathophysiological conditions (Harbauer et al., 2014). Moreover, it plays critical roles in surveilling translocation quality and in signalling import stress (Wasilewski et al., 2017).

\section{Pre-import chaperones}

The classical cytosolic Hsp70 and Hsp90 chaperones, their co-factors Sti1 and Ydj1, and ubiquilins (chaperone-like factors), associate with mitochondrial pre-proteins and also physically interact with the outer membrane components of the mitochondrial import channel (Deshaies et al., 1988; Young 
et al., 2003; Hoseini et al., 2016; Zanphorlin et al., 2016; Jores et al., 2018; Opaliñski et al., 2018). Supporting these physical interaction evidences, a genetic synthetic growth defect was observed between TOM and STI1, which encode protein forming an important scaffold, by simultaneously binding to Hsp70 and Hsp90 (Hoseini et al., 2016). Moreover, among the TOM components, a prominent role of Tom70 in import control has been suggested (Backes et al., 2018; Hansen et al., 2018; Opaliñski et al., 2018). In fact, Tom70 has a tetratricopeptide repeat, a domain known to bind to Hsp90 (Zanphorlin et al., 2016). Consistently, chemical inhibition of the Hsp70/90 interaction with Tom70 reduced the mitochondrial association of protein aggregates (Pavlov et al., 2018).

\section{Dual role of ubiquilins in control of protein import}

Ubiquilins were proposed to be involved at the earlier steps of mitochondrial protein biogenesis (Itakura et al., 2016; Whiteley et al., 2017). Ubiquilins are substrate receptors for proteasomal degradation, typically harbouring a ubiquitin-binding (UBA) domain for recognition of ubiquitinated cargo and a ubiquitin like domain, which is required for proteasomal targeting (Buchberger, 2002; Funakoshi et al., 2002). In line with their canonical function, they have been implicated in targeting mislocalized mitochondrial precursor proteins to the $26 \mathrm{~S}$ proteasome for degradation (Itakura et al., 2016; Whiteley et al., 2017). In addition, by binding to mitochondria-targeted membrane proteins, ubiquilins prevent their aggregation, thus exerting a chaperone like function. At this step ubiquilin binding still allows correct targeting of the bound protein. However, prolonged binding will result in ubiquitination of the bound protein by ubiquitin-ligases recruited by the UBA domain, and subsequent targeting for degradation (Itakura et al., 2016). Thus, ubiquilins not only function in targeting already ubiquitinated substrates for turnover but themselves exert an important role in triage of mitochondrial proteins (Fig. 12.4).

\section{Recognition of J-proteins by mitochondrial receptors}

Recent findings shed additional light on the early steps of mitochondrial protein biogenesis, by identifying how - once translated - mitochondrial proteins are targeted intracellularly to the surface of the organelle (Hansen et al., 2018; Opaliñski et al., 2018). Djp1, a J-protein that localizes to the surface of the endoplasmic reticulum, was found to contribute to mitochondrial protein import, in cooperation with pre-protein receptors. Therefore,

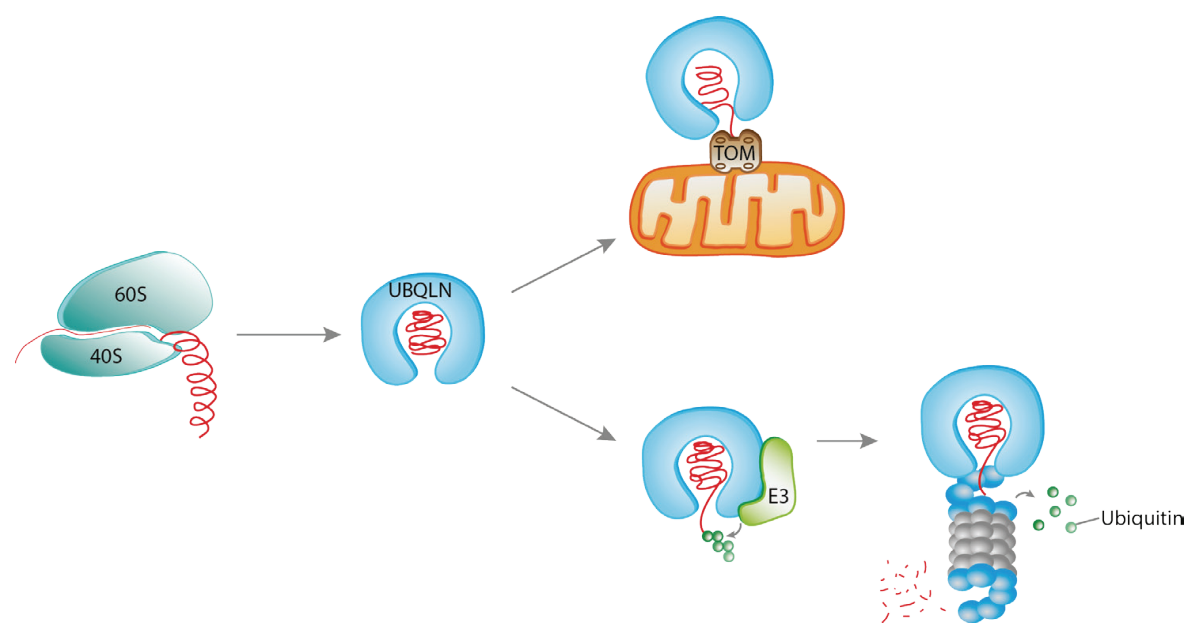

Figure 12.4 Dual role of ubiquilins in control of mitochondrial pre-proteins. The ubiquitine-proteasome receptors Ubiquilin 1 and 2 (UBQLN) guide mitochondrial membrane proteins after translation to the import channel. However, on prolonged binding, UBQLNs recruit E1, E2 and E3 ligase enzymes, required for their ubiquitination, allowing subsequent turnover by the proteasome. 
a pathway termed ER-Surf has been proposed, in which the endoplasmic reticulum provide a surface to capture mitochondrial preproteins (Fig. 12.5). In addition, the recognition by J-proteins of mitochondrial translocase components seems to be broad but specific, because although Djp1 cooperates with Tom70, Tom22 recruits the J-protein Xdj1 (Opaliñski et al., 2018). Consistent with an important role of J-proteins, Ydj1 and Sis1 were found to mediate import of beta-barrel proteins to the mitochondrial outer membrane (Jores et al., 2018).

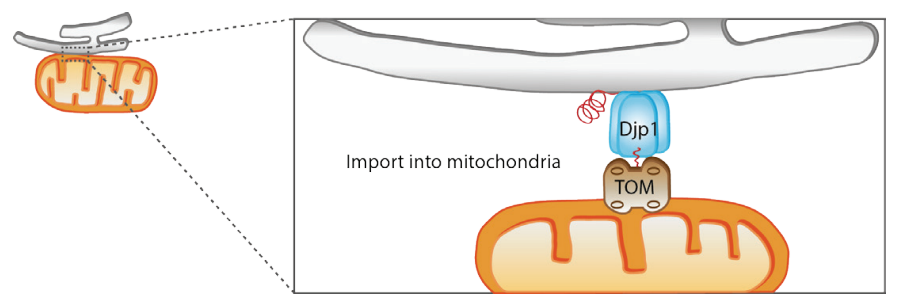

Figure 12.5 ER-associated J-Proteins promote mitochondrial import. The J-protein Djp1, which localizes at the ER surface, contributes with the TOM channel at the mitochondrial outer membrane to import mitochondrial pre-proteins.

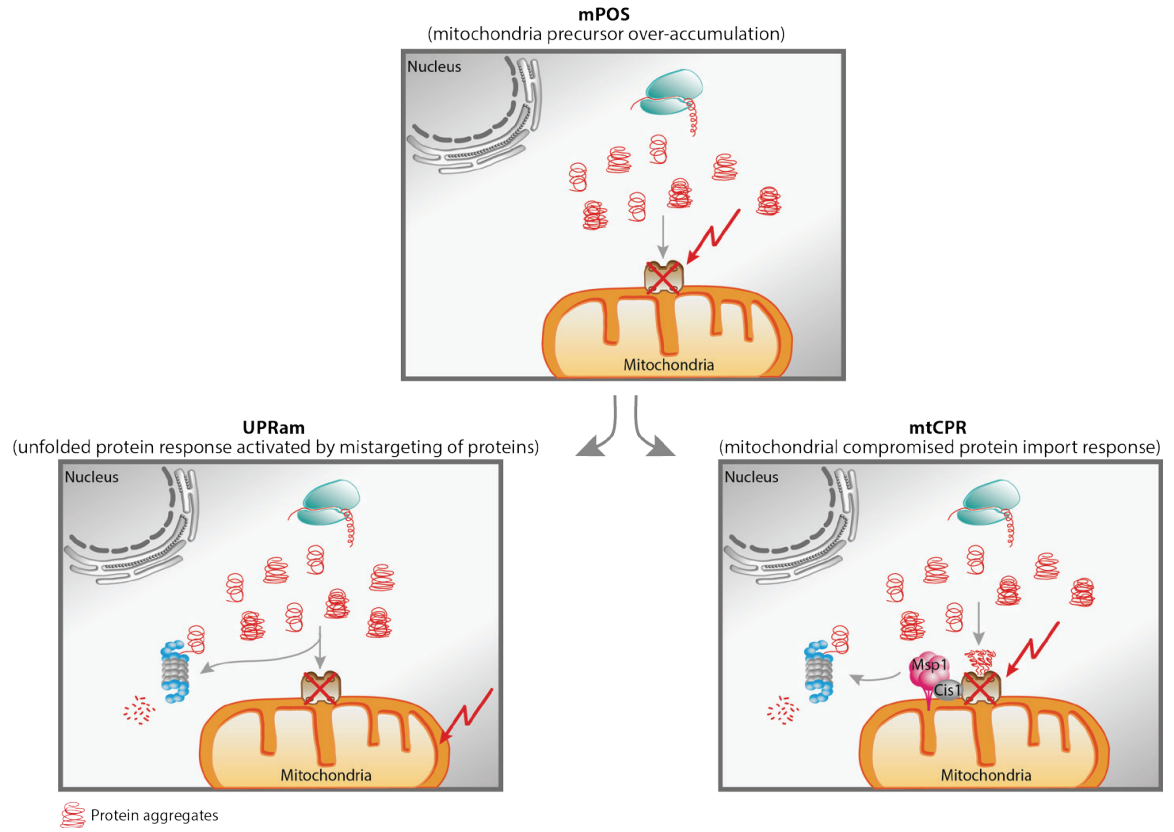

Figure 12.6 Cellular responses to mitochondrial import stress. Different quality control pathways are described maintaining cellular homeostasis on import overload at the mitochondrial surface. Protein import can be reduced due to intra- or extracellular stresses, causing the cytosolic accumulation of protein aggregates destined for the mitochondria (mPOS, mitochondrial precursor over-accumulation). The accumulation of unimported mitochondrial proteins can activate the UPRam (unfolded protein response activated by mis-targeting of proteins), which mediates the turnover of these proteins via the $26 \mathrm{~S}$ proteasome. Similarly, import clogging at the TOM channel activates the MitoCPR pathway (mitochondrial compromised protein import response). Thereby, the AAA-ATPase Msp1 interacts with the TOM channel via Cis1 and mediates the extraction of clogging proteins to the cytosol, where they are targeted for proteasomal turnover. 
UPRam - unfolded protein response activated by mistargeting of proteins

The global cellular responses caused by accumulation of mitochondrial precursor proteins in the cytosol were recently addressed, by provoking a defective protein import in the intermembrane space (Wrobel et al., 2015). Interestingly, mis-targeted mitochondrial proteins activated a concerted proteostatic response in the cytosol, whereby protein synthesis was inhibited and the proteasome was activated. Importantly, these responses were key in alleviated systemic pathology of the organelle and organismal death. In conclusion, UPRam allows buffering the consequences of physiological slowdown in mitochondrial protein import, thus promoting cellular survival under stress (Fig. 12.6).

Consistently, it was previously shown that reduced mitochondrial-membrane potential induced aggregation in the cytosol (Erjavec et al., 2013). A role of faulty protein import and accumulation of unprocessed mitochondrial proteins in the cytosol was equally proposed. Such defects generated by mitochondrial dysfunctions could be compensated for by a boost in cytosolic protein quality control, thus maintaining viability despite chronic failures in mitochondrial function (Erjavec et al., 2013). Another study suggested that defects in protein import lead to increased levels of reactive oxygen species, which in turn affect protein synthesis by modification of cytosolic ribosomes (Livnat-Levanon et al., 2014). Interestingly, reducing cytosolic synthesis of mitochondrial proteins has even been shown to reduce mitochondrial degeneration, emphasizing its impact on mitochondrial integrity (Wang et al., 2008).

mPOS - mitochondrial precursor overaccumulation stress

Simultaneously to UPRam, a study addressed the global consequences of aberrant accumulation of mitochondrial precursors in the cytosol, triggered either by impairing protein import or by clinically relevant mitochondrial damage (Wang and Chen, 2015). Consistent with UPRam, a cytosolic proteostatic network could be observed (Fig. 12.6). In particular, ribosomal biogenesis was modulated, where cap-dependent and thus major translation was down-regulated, to suppress protein synthesis. Moreover, cap-independent translation was up-regulated for a particular set of proteins that prevent ribosome assembly, thus reinforcing inhibition of general translation. Finally, this cytosolic network also suppressed cell death, confirming the physiological relevance of mPOS.

\section{MitoCPR - mitochondrial compromised protein import response}

An artificial precursor protein leading to clog of the protein import machineries revealed a role of the dislocase Msp1(yeast)/ATAD1(mammals) (Weidberg and Amon, 2018) (Fig. 12.6). Msp1 is a AAA-ATPase inserted at the outer membrane and facing the cytosol, assembling into a hexameric ring (Wohlever et al., 2017). An analysis of the genes transcriptionally correlated with import clogging allowed the identification of Cis1, which physically interacts with Msp1 but also with the Tom70 component of the outer membrane translocase. Clearance of the precursor proteins, which depended on Cis1, Tom70 and Msp1, also required the proteasome to degrade the non-imported proteins.

\section{IPTP - Interplay between mitochondrial translation and cytosolic responses}

Apart from the responses just described, primarily induced at the surface of mitochondria, a proteostasis retrograde mechanism initiated in the matrix was also reported. The unfolded protein response (UPR) had already revealed that mitochondrial stress can inhibit translation at the mitochondria. Now, a crosstalk mechanism of mitochondrial translation accuracy impacting on cytoplasmic proteostasis was also proposed (Suhm et al., 2018). Mitochondrial translation is signalled by a novel interorganellar proteostasis transcription program (IPTP), impacting chronological lifespan. Hyperaccurate mitochondrial translation stimulated Hsp104-mediated refolding and proteolytic capacity of a proteasomal model substrate. This infers that decreased accuracy of mitochondrial translation impaired management of cytosolic protein aggregates, eliciting a general transcription stress response. It also shows that cytosolic proteostasis, nuclear stress signalling and mitochondrial translation are closely coordinated in determining cellular homeostasis and lifespan (Suhm et al., 2018). 


\section{Turnover of mitochondrial proteins by the UPS}

In contrast to the nucleus, proteasomes are not present in mitochondria. Nevertheless, the UPS was shown to degrade some mitochondrial proteins after their insertion in the outer membrane, independently of the import surveillance mechanism described below. In the endoplasmic reticulum, ubiquitinated proteins are extracted to the cytoplasm by Cdc48/p97 to be degraded by the proteasome (Rape et al., 2001; Franz et al., 2014). This process is called ERAD (endoplasmic reticulum associated degradation). A similar mechanism was identified in mitochondria and named OMAD, for outer membrane associated degradation, in analogy to ERAD (Neutzner et al., 2007; Braun and Westermann, 2017).

\section{OMAD - extraction of cytosolic- exposed proteins by the cytosolic dislocase Cdc48}

As previously mentioned, $\mathrm{Cdc} 48$ assembles with a myriad of partners that assist the AAA protein in extracting proteins from complexes or membranes (Fig. 12.7). Cdc48 was suggested to extract the yeast mitofusin Fzol from mitochondria under oxidative stress conditions (Heo et al., 2010; Esaki and Ogura, 2012). In absence of external stress, Cdc48 formed a complex with Doal, Ufd1 and Npl4 to retrogradely translocate ubiquitinated membrane-anchored proteins to the cytoplasm, including tagged versions of Msp1 and Tom70 (Wu et al., 2016). Although tagged Fzo1 was also a MAD substrate (Wu et al., 2016), the endogenous protein is instead stabilized by endogenous Cdc48 (Simões et al., 2018), demonstrating limitations of working with tagged proteins, and thus accessing the real Cdc48 substrates. Nevertheless, the work from Wu et al. (2016) clearly highlights the importance of Cdc48 in quality control mechanisms at the outer membrane. In mammals, p97 was also required for the extraction and proteasomal turnover of outer membrane proteins, under damaging conditions, including mitofusins and Mcl-1 (Neutzner et al., 2007; Tanaka et al., 2010; Xu et al., 2011).

Interestingly, Cdc48 performs opposing roles to MAD, by instead increasing the stability of the Fzo 1 protein (Fig. 12.7). In fact, mitochondria form a dynamic network that is continuously remodelled by fusion and fission events. Fzo1, present at the

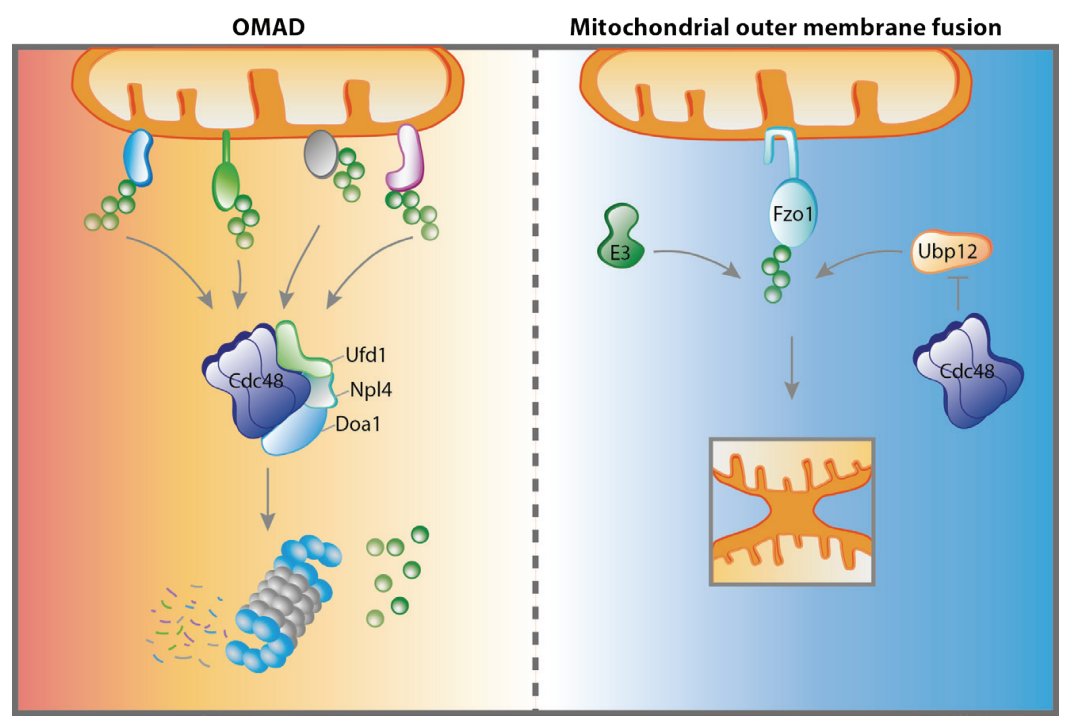

Figure 12.7 Dual roles of Cdc48 at the mitochondrial surface. The ubiquitin-specific AAA-ATPase Cdc48 maintains protein quality control at the mitochondrial outer membrane and regulates mitochondrial dynamics. On the one hand, Cdc48 acts as a cytosolic dislocase, which segregates ubiquitinated outer membrane proteins, allowing their degradation by the $26 \mathrm{~S}$ proteasome. On the other hand, Cdc48 protects ubiquitination on Fzo1, and controls a cascade of deubiquitinases, like Ubp12, thus promoting the mitochondrial outer membrane fusion process. 
mitochondrial outer membrane, is required for mitochondrial fusion. In contrast to MAD, Fzo1 was shown to be protected from the UPS by Cdc48 (Simões et al., 2018). Instead, Cdc48 was required for the turnover of a deubiquitinating enzyme which inhibits Fzo1. In addition, Cdc48 served as a binding platform, allowing crosstalk regulation between deubiquitinases and thus promoting membrane merging and mitochondrial fusion.

\section{Extraction of cytosolic-exposed proteins by the mitochondrial dislocase Msp1}

Similar to Cdc48/p97, Msp1/ATAD1 is a AAAATPase at the mitochondrial outer membrane that assembles into an hexameric ring, as previously mentioned (Schnell and Hebert, 2003). Therefore, Msp1/ATAD1 constitutes an alternative machinery to segregate substrates from the mitochondria. Indeed, recent findings showed that Msp1/ATAD1 participates in a local organelle surveillance pathway, to deal with proteins inappropriately inserted into mitochondria (Hegde, 2014; Okreglak and Walter, 2014; Opaliñski et al., 2014). Correct targeting of proteins to their respective organelles is a general challenge, given that the vast majority of organellar proteins are synthesized as precursors on cytosolic ribosomes and have to be transported to their intracellular destinations (Schnell and Hebert, 2003). This challenge is even bigger for tail-anchored proteins, i.e. with a single transmembrane segment at the C-terminus. Msp1 was shown to extract tail-anchored proteins mis-targeted from peroxisomes to mitochondria (Chen et al., 2014; Okreglak and Walter, 2014). Consistently, purified Msp1 drove ATP-dependent extraction of tailanchored proteins from the lipid bilayer (Wohlever et al., 2017). It is highly likely that the proteasome will degrade these mis-localized proteins, once extracted by Msp1, as it is the case in mitoCPR.

In conclusion, the Msp1/ATAD1 protease ensures the fidelity of organelle specific-localization of tail anchor proteins. Moreover, as previously described, it also functions in pre-protein clearance during mitochondrial import stress. This highlights critical functions of an outer membrane dislocase in maintaining mitochondrial integrity.

\section{IMS proteins}

The proteasome was also shown to degrade proteins present at the inner-membrane space, after their retrograde translocation back to the cytosol, mediated by Tom 40 (Bragoszewski et al., 2015) This is consistent with a previously observed accumulation of mitochondrial inner membrane proteins, upon chemical inhibition of the proteasomal activity (Radke et al., 2008). Interestingly, under those conditions, the inner membrane space protease $\mathrm{Omi} / \mathrm{HtrA} 2$ could degrade inner membrane proteins. However, it should be noted that mitochondrial proteases can also be sensitive to proteasomal inhibitors. Collectively, it is possible that faulty folding of inner membrane space proteins during import could lead to ubiquitination of their cytosolic exposed parts, providing access to the UPS. This is consistent with the observation that a fraction of newly synthesized intermembrane space precursors are degraded in the cytosol before reaching this subcompartment, event in the absence of stress-inducing conditions (Bragoszewski et al., 2013; Kowalski et al., 2018). In conclusion, the UPS plays a constitutive role for the biogenesis of intermembrane space proteins.

\section{Mitochondrial damage overload}

In addition to the previously described removal of individual proteins for proteasomal degradation, excessive damage can be repaired by eliminating whole mitochondrial fragments, by mitophagy, thus protecting the healthy mitochondria (Harper et al., 2018; Pickles et al., 2018). In addition, selected mitochondrial components can be eliminated from the mitochondrial network by mitochondria-derived vesicles or mitochondrial derived compartments (Sugiura et al., 2014; Hughes et al., 2016) (Fig. 12.8).

\section{Mitophagy}

The panoply of different mechanisms described, e.g. UPRmt, UPRam, POS, mitoCPR, allow coping with transient stress, still repairable at the level of the mal-functioning proteins. However, prolonged or acute stress conditions can no longer be reversed by these pathways, and mitochondria need to be eliminated by mitophagy, in order to restore cellular homeostasis. A prominent role of mitochondrial fission in allowing the detachment of damaged pieces from the entire network was recently proposed (Burman et al., 2017).

One of the early steps and hallmarks in mitophagy is the general ubiquitination of outer 


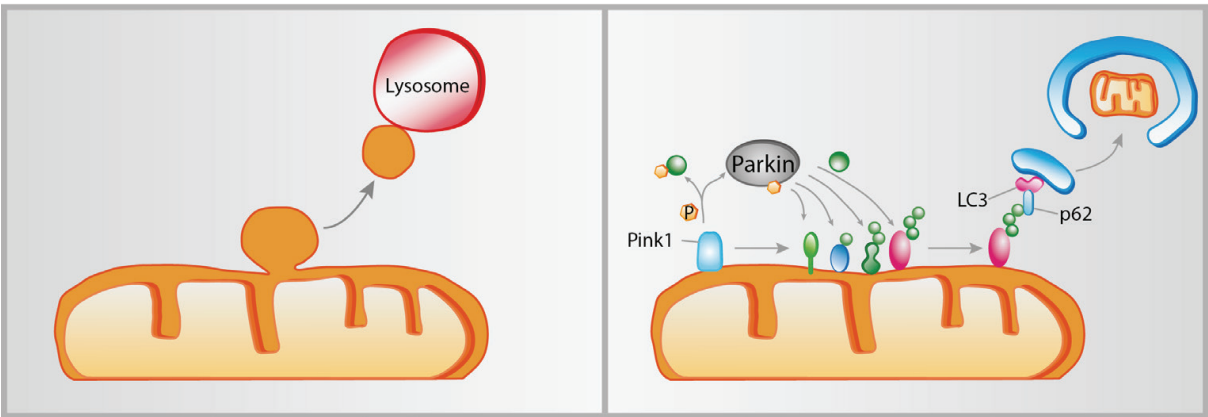

Figure 12.8 Elimination of damaged mitochondria. Local mitochondrial defects cause the budding of mitochondrial-derived vesicles (MDVs), which can consist only of the outer membrane, or of outer and inner membrane. Such vesicles, forming on oxidative stress, segregate from the mitochondrial network and fuse subsequently with lysosomes, where final degradation takes place. However, acute mitochondrial defects initiate the clearance of mitochondria via mitophagy. Loss of the mitochondrial membrane potential causes the accumulation of the kinase Pink1 at the outer membrane. Pink1 recruits and phosphorylates Parkin, which activates the E3 ligase. In addition, Pink1 phosphorylates ubiquitin, which is required for Parkin activation as well. Activated Parkin ubiquitylates several mitochondrial outer membrane proteins, which serve as a platform for the recruitment of the ubiquitin-like modifier LC3 via different adaptor autophagic receptors. LC3 lipidation with PE (Phosphatidylethanolamine) allows autophagosome expansion, which engulfs the whole damaged mitochondria. Subsequent mitochondrial degradation takes place within the lysosome on fusion of autophagosomes with lysosomes.

membrane proteins. This is believed to recruit several autophagy receptors and therefore mark mitochondria that should be eliminated. The most famous components performing this task are the E3 ligase Parkin and the mitochondrial kinase Pink1 (Pickles et al., 2018). In healthy mitochondria, Pink1 is imported into mitochondria, processed during import and then released to the cytosol and degraded by the $\mathrm{N}$-end rule. In contrast, upon loss of membrane potential, the kinase is arrested due to import failure, thus integrating in the outer membrane, and exposing the catalytic domain to the cytosol (Matsuda et al., 2010; Vives-Bauza et al., 2010). There, it phosphorylates Parkin at its ubiquitin-like domain, which changes its conformation and leads to enzymatic activation. Moreover, Pink1 phosphorylates serine 65 of ubiquitin chains assembled by Parkin at the outer membrane, further increasing Parkin recruitment to the mitochondria and activation, by feedforward loop mechanisms. These chains bind several receptors like Optineurin, NDP52 and p62, which then engage the autophagic machinery and culminates by releasing mitochondria into the lysosome for destruction (McWilliams and Muqit, 2017) (Geisler et al., 2010; Narendra et al., 2010; Lazarou et al., 2015; Khaminets et al., 2016). In addition to Parkin, other E3 ligases stimulate mitophagy (Covill-Cooke et al., 2018). For example, the outer membrane RING ligase March5 induced mitophagy on hypoxic conditions, together with the autophagic receptor FUNDC1 (Chen et al., 2017). In addition, March5 has many additional physiological functions (Covill-Cooke et al., 2018). Finally, ubiquitin-independent mitophagy pathways have also been described as for example the role of the ATG8 receptor NIX in hypoxia (Khaminets et al., 2016).

\section{Mitochondrial-derived vesicles}

In contrast to mitophagy, where the whole organelle is degraded, mitochondria can also dispose content in the form of vesicles, called MDVs (mitochondria-derived vesicles), which transport proteins and lipids to other cellular organelles (Sugiura et al., 2014). Mitochondria can form different types of vesicles, with different cargoes and also with different cellular destinations, thus facilitating intracellular communication. In yeast, vesicles allowing selective degradation of a protein subset were also found, suggesting that budding of mitochondria could be a conserved mechanism (Hughes et al., 2016). Pink1 and Parkin are also involved in the formation of MDVs containing oxidized cargo and formed after oxidative stress. 
Consistent with their quality control roles, these MDVs were destined to the lysosomes, suggesting a similar role to mitophagy of Pink1 and Parkin, just more confined and not so extreme. Interestingly, however, a role of Pink1 and Parkin in repressing vesicle formation was also recently reported (Matheoud et al., 2016). Indeed, MDVs containing antigens were negatively regulated by Pink 1 and Parkin. These MDVs were targeted to the cellular surface, to present the cargo on major histocompatibility (MHC) class I molecules, triggering an immune response. Consistently, Pink1 and Parkin also prevented the activation of an inflammatory response caused by excessive mutations in the mitochondrial DNA (Sliter et al., 2018). Finally, other roles of Parkin have been proposed, as for example in mitochondrial trafficking along neurons (Scarffe et al., 2014).

\section{Role of ribosomal quality control (RQC) in mitochondria}

Fidelity of protein synthesis is essential for mitochondrial function, since the vast majority of mitochondrial proteins are synthesized by cytosolic ribosomes. However, protein synthesis at ribosomes can go wrong, resulting in aberrant translation products, which are subjected to ribosomal quality control (RQC) (Brandman and Hegde, 2016) (Fig. 12.9). Failure in RQC of mitochondrial proteins results in defective proteins, which are still imported into mitochondria and interfere with mitochondrial proteostasis (Izawa et al., 2017). RQC monitors ribosomal activity and is activated on stalling of translation. Potential causes for stalling are damaged or truncated mRNAs, particular mRNA sequences including poly(A)tails, excessive mRNA secondary structures and insufficient amounts of amino acids or tRNAs (Brandman and Hegde, 2016). As a consequence of stalling, ribosomes are disassembled and the potentially defective mRNA is degraded, as well as the nascent polypeptide chain.

\section{$R Q C$}

The first step of RQC is the splitting of the ribosome, resulting in a $60 \mathrm{~S}$ ribosomal subunit bound to the nascent polypeptide chain. This complex is then recognized by the RQC complex, which consists of Rqc1, Rqc2, the E3 ubiquitin ligase Ltn1 (Listerin in mammals) and Cdc48 with its co-factors $\mathrm{Npl} 4$ and Ufd1 (Brandman et al., 2012). The function of Ltn 1 is to ubiquitylate the stalled polypeptide at the ribosomal exit site, resulting in proteasomal degradation (Bengtson and Joazeiro, 2010). This process requires the action of $\mathrm{Cdc} 48$ to extract the ubiquitinated nascent chain from the $60 \mathrm{~S}$ ribosome (Defenouillère et al., 2013). In addition to ubiquitination, the stalled polypeptide can be further modified by addition of multiple alanine and threonine residues, at the $\mathrm{C}$-terminal. The synthesis of this amino acid extension -termed CAT-tail (c-terminal Alanine Threonine tail) occurs independently of mRNA or 40S subunits. Instead, it depends on the recruitment of charged t-RNAs by Rqc2 (Shen et al., 2015). CAT-tails increase the probability of exposing lysines present
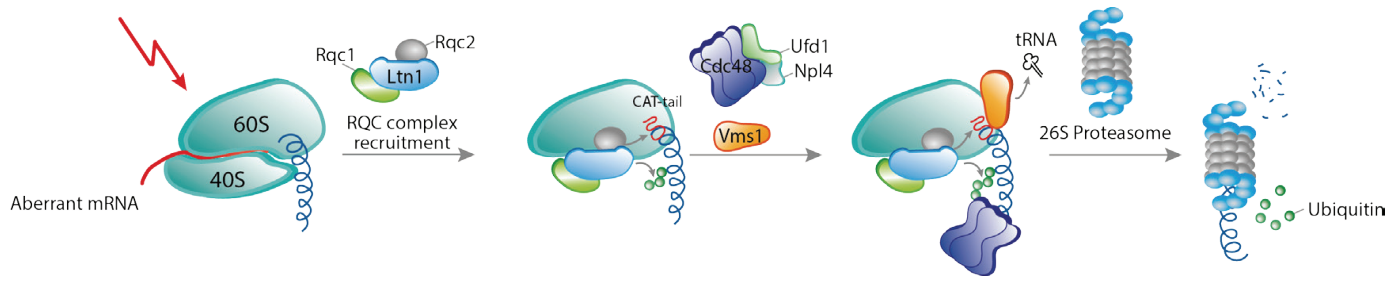

Figure 12.9 Ribosomal quality control. Translation of defective proteins requires the ribosomal quality control (RQC) machinery. On stalling of translation, ribosomes disassemble resulting in the 60S subunit bound to the nascent polypeptide chain. This recruits the RQC complex consisting of Rqc1, Rqc2 and Ltn1. Rqc1 recruits Cdc48 for the segregation of the polypeptide chain from the 60S subunit, which is subsequently degraded via the 26S proteasome. Rqc2 recruits charged tRNAs for the assembly of a CAT tail at the C-terminus of the nascent poly-peptide. The CAT tail increases exposure of lysine residues, which are ubiquitinated by the E3 ligase Ltn1, thus addressing the stalled polypeptide for proteasomal degradation. Additionally, the peptidyltRNA hydrolase Vms1 mediates the removal of the bound tRNA from the nascent chain, facilitating release from the ribosome. 
on the stalled chain to Ltn1. In turn, Rqc1 recruits $\mathrm{Cdc} 48$ to ribosomal subunits. When ubiquitination and degradation are compromised, the nascent polypeptides are still released from the ribosome and form CAT-tail dependent aggregates in the cytosol (Choe et al., 2016; Defenouillère et al., 2016; Yonashiro et al., 2016).

\section{Role of Vms1/ANKZF1 in RQC}

Another factor recently implicated in RQC is Vms1. Initially, Vms1 had been identified as a cofactor recruiting $\mathrm{Cdc} 48$ to mitochondria on stress (Heo et al., 2010). Despite being a cytosolic soluble protein, Vms1 translocates into mitochondria on oxidative stress, dependent on ergosterol peroxide, suggesting the presence of an oxidized sterol receptor at the outer membrane (Nielson et al., 2017). Further studies revealed that Vms1 binds to ribosomes and the RQC complex, suggesting a role of RQC in mitochondrial quality control and a general function of Vms1 in RQC (Izawa et al., 2017). Indeed, Vms1 and its human homologue ANKZF1 have then been identified as peptidyl-tRNA hydrolase, required to remove the bound tRNA from the nascent chain, thereby facilitating release from the ribosome (Zurita Rendón et al., 2018; Verma et al., 2018).

\section{Mitochondrial functions of $\mathrm{Vms1/}$ ANKZF1}

Vms1, despite being a general factor in RQC, appears to particularly affect mitochondrial proteostasis (Izawa et al., 2017). Indeed, a combined deletion of the genes encoding the proteins Vms1 and Ltn1 resulted in severe growth inhibition under respiratory conditions. This growth defect was entirely dependent on CAT-tail formation by Rqc2. Consistently, aggregation and sequestration were observed, mainly of mitochondrial proteins, highlighting the importance of RQC for mitochondrial integrity (Izawa et al., 2017). Conversely, overexpression of Vms1 reduced the Rqc2-dependent aggregation, by inhibiting Rqc2 binding to ribosomes. The strong impact of $\mathrm{Vms} 1$ on mitochondrial proteostasis might be explained by differences in the fate of cytosolic and mitochondrial proteins. Nascent mitochondrial proteins might still be partially imported, thanks on their $\mathrm{N}$-terminal mitochondrial targeting sequence. This might reduce the efficiency of Ltn1-dependent ubiquitination on ribosome stalling. Consequently, an increase in the requirement of $\mathrm{Vms} 1$ in RQC, to clear nascent mitochondrial polypeptides and prevent clogging of the import channel, is not surprising. Though initially identified as a Cdc48interacting protein (Heo et al., 2010), the function of Vms1 in RQC was reported to be independent of Cdc48 (Verma et al., 2018). In contrast, the general role of Vms1 in RQC was shown to depend on Cdc48 interaction (Izawa et al., 2017).

\section{Concluding remarks}

Increased proteotoxic burden is a hallmark of neurodegeneration. The main cellular strategies to cope with proteotoxic stress are to increase the levels of chaperones, activate proteolytic pathways and reduce protein synthesis. Recent events highlighted that these main strategies come in different flavours and involve crosstalk between different cellular compartments. Knowing that mitochondria joined this team considerably broadens our knowledge of the ubiquitin dependent and independent crossfunctional cellular stress response mechanisms. Hopefully these findings will get us closer to therapies for the myriad of diseases caused by insufficient handling of protein damage.

\section{Acknowledgements}

We are grateful to T. Tatsuta for critical reading of the manuscript. This work was supported by grants of the Deutsche Forschungsgemeinschaft (DFG; ES338/3-1, CRC 1218 TP A03; to M.E.-H.), of the Fritz-Thyssen foundation (10.15.1.018MN, to M.E.-H.), of the Center for Molecular Medicine Cologne (CMMC; CAP14, to M.E.-H.), was funded under the Institutional Strategy of the University of Cologne within the German Excellence Initiative (ZUK 81/1, to M.E.-H.) and benefited from funds of the Faculty of Mathematics and Natural Sciences, attributed to M.E.-H.

\section{References}

Aguilaniu, H., Gustafsson, L., Rigoulet, M., and Nyström, T. (2003). Asymmetric inheritance of oxidatively damaged proteins during cytokinesis. Science 299, 1751-1753. https://doi.org/10.1126/science.1080418.

Almajan, E.R., Richter, R., Paeger, L., Martinelli, P., Barth, E., Decker, T., Larsson, N.G., Kloppenburg, P., Langer, T., and Rugarli, E.I. (2012). AFG3L2 supports mitochondrial protein synthesis and Purkinje cell 
survival. J. Clin. Invest. 122, 4048-4058. https://doi. org/10.1172/JCI64604.

Amm, I., Sommer, T., and Wolf, D.H. (2014). Protein quality control and elimination of protein waste: the role of the ubiquitin-proteasome system. Biochim. Biophys. Acta 1843, 182-196. https://doi.org/10.1016/j. bbamcr.2013.06.031.

Anand, R., Wai, T., Baker, M.J., Kladt, N., Schauss, A.C., Rugarli, E., and Langer, T. (2014). The i-AAA protease YME1L and OMA1 cleave OPA1 to balance mitochondrial fusion and fission. J. Cell Biol. 204, 919-929. https://doi.org/10.1083/jcb.201308006.

Backes, S., Hess, S., Boos, F., Woellhaf, M.W., Gödel, S., Jung, M., Mühlhaus, T., and Herrmann, J.M. (2018). Tom70 enhances mitochondrial preprotein import efficiency by binding to internal targeting sequences. J. Cell Biol. 217, 1369-1382. https://doi.org/10.1083/jcb.201708044.

Balchin, D., Hayer-Hartl, M., and Hartl, F.U. (2016). In vivo aspects of protein folding and quality control. Science 353, aac4354. https://doi.org/10.1126/science. aac4354.

Baldi, S., Bolognesi, A., Meinema, A.C., and Barral, Y. (2017). Heat stress promotes longevity in budding yeast by relaxing the confinement of age-promoting factors in the mother cell. Elife 6, e28329. https://doi. org/10.7554/eLife.28329.

Bard, J.A.M., Goodall, E.A., Greene, E.R., Jonsson, E., Dong, K.C., and Martin, A. (2018). Structure and Function of the 26S Proteasome. Annu. Rev. Biochem. 87, 697-724. https://doi.org/10.1146/annurevbiochem-062917-011931.

Bender, T., Lewrenz, I., Franken, S., Baitzel, C., and Voos, W. (2011). Mitochondrial enzymes are protected from stress-induced aggregation by mitochondrial chaperones and the Pim1/LON protease. Mol. Biol. Cell 22, 541554. https://doi.org/10.1091/mbc.E10-08-0718.

Bengtson, M.H., and Joazeiro, C.A. (2010). Role of a ribosome-associated E3 ubiquitin ligase in protein quality control. Nature 467, 470-473. https://doi. org/10.1038/nature09371.

Böckler, S., Chelius, X., Hock, N., Klecker, T., Wolter, M., Weiss, M., Braun, R.J., and Westermann, B. (2017). Fusion, fission, and transport control asymmetric inheritance of mitochondria and protein aggregates. J. Cell Biol. 216, 2481-2498. https://doi.org/10.1083/ jcb.201611197.

Bragoszewski, P., Gornicka, A., Sztolsztener, M.E., and Chacinska, A. (2013). The ubiquitin-proteasome system regulates mitochondrial intermembrane space proteins. Mol. Cell. Biol. 33, 2136-2148. https://doi. org/10.1128/MCB.01579-12.

Bragoszewski, P., Wasilewski, M., Sakowska, P., Gornicka, A., Böttinger, L., Qiu, J., Wiedemann, N., and Chacinska, A. (2015). Retro-translocation of mitochondrial intermembrane space proteins. Proc. Natl. Acad. Sci. U.S.A. 112, 7713-7718. https://doi.org/10.1073/ pnas. 1504615112 .

Brandman, O., and Hegde, R.S. (2016). Ribosomeassociated protein quality control. Nat. Struct. Mol. Biol. $23,7-15$.

Brandman, O., Stewart-Ornstein, J., Wong, D., Larson, A., Williams, C.C., Li, G.W., Zhou, S., King, D., Shen, P.S., Weibezahn, J., et al. (2012). A ribosome-bound quality control complex triggers degradation of nascent peptides and signals translation stress. Cell 151, 1042-1054. https://doi.org/10.1016/j.cell.2012.10.044.

Braun, R.J., and Westermann, B. (2017). With the Help of MOM: Mitochondrial Contributions to Cellular Quality Control. Trends Cell Biol. 27, 441-452.

Braymer, J.J., and Lill, R. (2017). Iron-sulfur cluster biogenesis and trafficking in mitochondria. J. Biol. Chem. 292, 12754-12763. https://doi.org/10.1074/ jbc.R117.787101.

Bruderek, M., Jaworek, W., Wilkening, A., Rüb, C., Cenini, G., Förtsch, A., Sylvester, M., and Voos, W. (2018). IMiQ: a novel protein quality control compartment protecting mitochondrial functional integrity. Mol. Biol. Cell 29, 256-269. https://doi.org/10.1091/mbc.E1701-0027.

Buchberger, A. (2002). From UBA to UBX: new words in the ubiquitin vocabulary. Trends Cell Biol. 12, 216-221.

Burman, J.L., Pickles, S., Wang, C., Sekine, S., Vargas, J.N.S., Zhang, Z., Youle, A.M., Nezich, C.L., Wu, X., Hammer, J.A., et al. (2017). Mitochondrial fission facilitates the selective mitophagy of protein aggregates. J. Cell Biol. 216, 3231-3247. https://doi.org/10.1083/ jcb.201612106.

Cardenas-Rodriguez, M., Chatzi, A., and Tokatlidis, K. (2018). Iron-sulfur clusters: from metals through mitochondria biogenesis to disease. J. Biol. Inorg. Chem. 23, 509-520. https://doi.org/10.1007/s00775-0181548-6.

Chen, Y.C., Umanah, G.K., Dephoure, N., Andrabi, S.A., Gygi, S.P., Dawson, T.M., Dawson, V.L., and Rutter, J. (2014). Msp1/ATAD1 maintains mitochondrial function by facilitating the degradation of mislocalized tail-anchored proteins. EMBO J. 33, 1548-1564. https://doi.org/10.15252/embj.201487943.

Chen, Z., Liu, L., Cheng, Q., Li, Y., Wu, H., Zhang, W., Wang, Y., Sehgal, S.A., Siraj, S., Wang, X., et al. (2017). Mitochondrial E3 ligase MARCH5 regulates FUNDC1 to fine-tune hypoxic mitophagy. EMBO Rep. 18, 495509. https://doi.org/10.15252/embr.201643309.

Cheng, M.Y., Hartl, F.U., Martin, J., Pollock, R.A., Kalousek, F., Neupert, W., Hallberg, E.M., Hallberg, R.L., and Horwich, A.L. (1989). Mitochondrial heat-shock protein hsp60 is essential for assembly of proteins imported into yeast mitochondria. Nature 337, 620625. https://doi.org/10.1038/337620a0.

Choe, Y.J., Park, S.H., Hassemer, T., Körner, R., VincenzDonnelly, L., Hayer-Hartl, M., and Hartl, F.U. (2016). Failure of RQC machinery causes protein aggregation and proteotoxic stress. Nature 531, 191-195. https:// doi.org/10.1038/nature16973.

Chung, C.G., Lee, H., and Lee, S.B. (2018). Mechanisms of protein toxicity in neurodegenerative diseases. Cell. Mol. Life Sci. 75, 3159-3180. https://doi.org/10.1007/ s00018-018-2854-4.

Clausen, T., Kaiser, M., Huber, R., and Ehrmann, M. (2011). HTRA proteases: regulated proteolysis in protein quality control. Nat. Rev. Mol. Cell Biol. 12, 152-162. https:// doi.org/10.1038/nrm3065.

Clay, L., Caudron, F., Denoth-Lippuner, A., Boettcher, B., Buvelot Frei, S., Snapp, E.L., and Barral, Y. (2014). A sphingolipid-dependent diffusion barrier confines ER 
stress to the yeast mother cell. Elife 3, e01883. https:// doi.org/10.7554/eLife.01883.

Coelho, M., Lade, S.J., Alberti, S., Gross, T., and Tolić, I.M. (2014). Fusion of protein aggregates facilitates asymmetric damage segregation. PLOS Biol. 12, e1001886. pbio. 1001886.

Couvillion, M.T., Soto, I.C., Shipkovenska, G., and Churchman, L.S. (2016). Synchronized mitochondrial and cytosolic translation programs. Nature 533, 499503. https://doi.org/10.1038/nature18015.

Covill-Cooke, C., Howden, J.H., Birsa, N., and Kittler, J.T. (2018). Ubiquitination at the mitochondria in neuronal health and disease. Neurochem. Int. 117, 55-64.

Craig, E.A. (2018). Hsp70 at the membrane: driving protein translocation. BMC Biol. 16, 11. https://doi. org/10.1186/s12915-017-0474-3.

D'Amico, D., Sorrentino, V., and Auwerx, J. (2017). Cytosolic Proteostasis Networks of the Mitochondrial Stress Response. Trends Biochem. Sci. 42, 712-725.

Defenouillère, Q. Yao, Y., Mouaikel, J., Namane, A., Galopier, A., Decourty, L., Doyen, A., Malabat, C., Saveanu, C., Jacquier, A., et al. (2013). Cdc48-associated complex bound to $60 \mathrm{~S}$ particles is required for the clearance of aberrant translation products. Proc. Natl. Acad. Sci. U.S.A. 110, 5046-5051. https://doi.org/10.1073/ pnas. 1221724110 .

Defenouillère, Q. Zhang, E., Namane, A., Mouaikel, J., Jacquier, A., and Fromont-Racine, M. (2016). Rqc1 and Ltn1 Prevent C-terminal Alanine-Threonine Tail (CAT-tail)-induced Protein Aggregation by Efficient Recruitment of Cdc48 on Stalled 60 S Subunits. J. Biol. Chem. 291, 12245-12253. https://doi.org/10.1074/ jbc.M116.722264.

Deshaies, R.J., Koch, B.D., Werner-Washburne, M., Craig, E.A., and Schekman, R. (1988). A subfamily of stress proteins facilitates translocation of secretory and mitochondrial precursor polypeptides. Nature 332, 800-805. https://doi.org/10.1038/332800a0.

D'Souza, A.R., and Minczuk, M. (2018). Mitochondrial transcription and translation: overview. Essays Biochem. 62, 309-320. https://doi.org/10.1042/EBC20170102.

Dudek, J., Rehling, P., and van der Laan, M. (2013). Mitochondrial protein import: common principles and physiological networks. Biochim. Biophys. Acta 1833, 274-285. https://doi.org/10.1016/j. bbamcr.2012.05.028.

Dunker, A.K., Silman, I., Uversky, V.N., and Sussman, J.L. (2008). Function and structure of inherently disordered proteins. Curr. Opin. Struct. Biol. 18, 756-764. https:// doi.org/10.1016/j.sbi.2008.10.002.

Dunn, C.D., Tamura, Y., Sesaki, H., and Jensen, R.E. (2008). Mgr3p and Mgrlp are adaptors for the mitochondrial i-AAA protease complex. Mol. Biol. Cell 19, 5387-5397. https://doi.org/10.1091/mbc.E08-01-0103.

Erjavec, N., Bayot, A., Gareil, M., Camougrand, N., Nystrom, T., Friguet, B., and Bulteau, A.L. (2013). Deletion of the mitochondrial Pim1/Lon protease in yeast results in accelerated aging and impairment of the proteasome. Free Radic. Biol. Med. 56, 9-16. https:// doi.org/10.1016/j.freeradbiomed.2012.11.019.

Esaki, M., and Ogura, T. (2012). Cdc48p/p97mediated regulation of mitochondrial morphology is Vmslp-independent. J. Struct. Biol. 179, 112-120. https://doi.org/10.1016/j.jsb.2012.04.017.

Escobar-Henriques, M., and Langer, T. (2014). Dynamic survey of mitochondria by ubiquitin. EMBO Rep. 15, 231-243. https://doi.org/10.1002/embr.201338225.

Falkenberg, M., Larsson, N.G., and Gustafsson, C.M. (2007). DNA replication and transcription in mammalian mitochondria. Annu. Rev. Biochem. 76, 679-699. https://doi.org/10.1146/annurev. biochem.76.060305.152028.

Fernández-Fernández, M.R., Gragera, M., Ochoa-Ibarrola, L., Quintana-Gallardo, L., and Valpuesta, J.M. (2017). Hsp70 - a master regulator in protein degradation. FEBS Lett. 591, 2648-2660. https://doi.org/10.1002/18733468.12751 .

Franz, A., Ackermann, L., and Hoppe, T. (2014). Create and preserve: proteostasis in development and aging is governed by Cdc48/p97/VCP. Biochim. Biophys. Acta 1843, 205-215. https://doi.org/10.1016/j. bbamcr.2013.03.031.

Funakoshi, M., Sasaki, T., Nishimoto, T., and Kobayashi, H. (2002). Budding yeast Dsk2p is a polyubiquitinbinding protein that can interact with the proteasome. Proc. Natl. Acad. Sci. U.S.A. 99, 745-750. https://doi. org/10.1073/pnas.012585199.

Gautschi, M., Lilie, H., Fünfschilling, U., Mun, A., Ross, S., Lithgow, T., Rücknagel, P., and Rospert, S. (2001). RAC, a stable ribosome-associated complex in yeast formed by the DnaK-DnaJ homologs Sszlp and zuotin. Proc. Natl. Acad. Sci. U.S.A. 98, 3762-3767. https://doi. org/10.1073/pnas.071057198.

Geisler, S., Holmström, K.M., Skujat, D., Fiesel, F.C., Rothfuss, O.C., Kahle, P.J., and Springer, W. (2010). PINK1/Parkin-mediated mitophagy is dependent on VDAC1 and p62/SQSTM1. Nat. Cell Biol. 12, 119-131. https://doi.org/10.1038/ncb2012.

Gerdes, F., Tatsuta, T., and Langer, T. (2012). Mitochondrial AAA proteases - towards a molecular understanding of membrane-bound proteolytic machines. Biochim. Biophys. Acta 1823, 49-55. https://doi.org/10.1016/j. bbamcr.2011.09.015.

Germain, D. (2008). Ubiquitin-dependent and -independent mitochondrial protein quality controls: implications in ageing and neurodegenerative diseases. Mol. Microbiol. 70, 1334-1341. https://doi. org/10.1111/j.1365-2958.2008.06502.x.

Green, D.R., Galluzzi, L., and Kroemer, G. (2014). Cell biology. Metabolic control of cell death. Science 345, 1250256. https://doi.org/10.1126/science.1250256.

Guaragnella, N., Coyne, L.P., Chen, X.J., and Giannattasio, S. (2018). Mitochondria-cytosol-nucleus crosstalk: learning from Saccharomyces cerevisiae. FEMS Yeast Res. 18, . https://doi.org/10.1093/femsyr/foy088.

Guo, Q. Lehmer, C., Martínez-Sánchez, A., Rudack, T., Beck, F., Hartmann, H., Pérez-Berlanga, M., Frottin, F., Hipp, M.S., Hartl, F.U., et al. (2018). In Situ Structure of Neuronal C9orf72 Poly-GA Aggregates Reveals Proteasome Recruitment. Cell 172, 696-705.e12.

Hamon, M.P., Bulteau, A.L., and Friguet, B. (2015). Mitochondrial proteases and protein quality control in ageing and longevity. Ageing Res. Rev. 23, 56-66.

Hansen, K.G., Aviram, N., Laborenz, J., Bibi, C., Meyer, M., Spang, A., Schuldiner, M., and Herrmann, J.M. (2018). 
An ER surface retrieval pathway safeguards the import of mitochondrial membrane proteins in yeast. Science 361, 1118-1122. https://doi.org/10.1126/science.aar8174.

Harbauer, A.B., Zahedi, R.P., Sickmann, A., Pfanner, N., and Meisinger, C. (2014). The protein import machinery of mitochondria-a regulatory hub in metabolism, stress, and disease. Cell Metab. 19, 357-372. https://doi. org/10.1016/j.cmet.2014.01.010.

Harper, J.W., Ordureau, A., and Heo, J.M. (2018). Building and decoding ubiquitin chains for mitophagy. Nat. Rev. Mol. Cell Biol. 19, 93-108. https://doi.org/10.1038/ nrm.2017.129.

Hartl, F.U. (1996). Molecular chaperones in cellular protein folding. Nature 381, 571-579. https://doi. org/10.1038/381571a0.

Hartl, F.U., Bracher, A., and Hayer-Hartl, M. (2011). Molecular chaperones in protein folding and proteostasis. Nature 475, 324-332. https://doi. org/10.1038/nature 10317.

Haynes, C.M., Petrova, K., Benedetti, C., Yang, Y., and Ron, D. (2007). ClpP mediates activation of a mitochondrial unfolded protein response in C. elegans. Dev. Cell 13, 467-480.

Hegde, R.S. (2014). Msp1: patrolling mitochondria for lost proteins. EMBO J. 33, 1509-1510. https://doi. org/10.15252/embj.201488930.

Heo, J.M., Livnat-Levanon, N., Taylor, E.B., Jones, K.T., Dephoure, N., Ring, J., Xie, J., Brodsky, J.L., Madeo, F., Gygi, S.P., et al. (2010). A stress-responsive system for mitochondrial protein degradation. Mol. Cell 40, 465480. https://doi.org/10.1016/j.molcel.2010.10.021.

Higuchi, R., Vevea, J.D., Swayne, T.C., Chojnowski, R., Hill, V., Boldogh, I.R., and Pon, L.A. (2013). Actin dynamics affect mitochondrial quality control and aging in budding yeast. Curr. Biol. 23, 2417-2422. https://doi. org/10.1016/j.cub.2013.10.022.

Higuchi-Sanabria, R., Frankino, P.A., Paul, J.W., Tronnes, S.U., and Dillin, A. (2018). A Futile Battle? Protein Quality Control and the Stress of Aging. Dev. Cell 44, 139-163.

Hill, S.M., Hanzén, S., and Nyström, T. (2017). Restricted access: spatial sequestration of damaged proteins during stress and aging. EMBO Rep. 18, 377-391. https://doi. org/10.15252/embr.201643458.

Hoseini, H., Pandey, S., Jores, T., Schmitt, A., Franz-Wachtel, M., Macek, B., Buchner, J., Dimmer, K.S., and Rapaport, D. (2016). The cytosolic cochaperone Sti1 is relevant for mitochondrial biogenesis and morphology. FEBS J. 283, 3338-3352. https://doi.org/10.1111/febs.13813.

Hughes, A.L., Hughes, C.E., Henderson, K.A., Yazvenko, N., and Gottschling, D.E. (2016). Selective sorting and destruction of mitochondrial membrane proteins in aged yeast. Elife 5, e13943. https://doi.org/10.7554/ eLife.13943.

Itakura, E., Zavodszky, E., Shao, S., Wohlever, M.L., Keenan, R.J., and Hegde, R.S. (2016). Ubiquilins chaperone and triage mitochondrial membrane proteins for degradation. Mol. Cell 63, 21-33. https://doi. org/10.1016/j.molcel.2016.05.020.

Izawa, T., Park, S.H., Zhao, L., Hartl, F.U., and Neupert, W. (2017). Cytosolic protein vms1 links ribosome quality control to mitochondrial and cellular homeostasis. Cell 171, 890-903.e18.
Jakobs, S., and Wurm, C.A. (2014). Super-resolution microscopy of mitochondria. Curr. Opin. Chem. Biol. 20, 9-15. https://doi.org/10.1016/j.cbpa.2014.03.019.

Jores, T., Lawatscheck, J., Beke, V., Franz-Wachtel, M., Yunoki, K., Fitzgerald, J.C., Macek, B., Endo, T., Kalbacher, H., Buchner, J., et al. (2018). Cytosolic Hsp70 and Hsp40 chaperones enable the biogenesis of mitochondrial $\beta$-barrel proteins. J. Cell Biol. 217, 3091-3108. https://doi.org/10.1083/jcb.201712029.

Jovaisaite, V., and Auwerx, J. (2015). The mitochondrial unfolded protein response - synchronizing genomes. Curr. Opin. Cell Biol. 33, 74-81. https://doi. org/10.1016/j.ceb.2014.12.003.

Kampinga, H.H., and Craig, E.A. (2010). The HSP70 chaperone machinery: J proteins as drivers of functional specificity. Nat. Rev. Mol. Cell Biol. 11, 579-592. https://doi.org/10.1038/nrm2941.

Kang, P.J., Ostermann, J., Shilling, J., Neupert, W., Craig, E.A., and Pfanner, N. (1990). Requirement for hsp70 in the mitochondrial matrix for translocation and folding of precursor proteins. Nature 348, 137-143. https://doi. org/10.1038/348137a0.

Kauppila, T.E.S., Kauppila, J.H.K., and Larsson, N.G. (2017). Mammalian mitochondria and aging: an update. Cell Metab. 25, 57-71.

Kerscher, O., Felberbaum, R., and Hochstrasser, M. (2006). Modification of proteins by ubiquitin and ubiquitin-like proteins. Annu. Rev. Cell Dev. Biol. 22, 159-180.https:// doi.org/10.1146/annurev.cellbio.22.010605.093503.

Khaminets, A., Behl, C., and Dikic, I. (2016). Ubiquitindependent and independent signals in selective autophagy. Trends Cell Biol. 26, 6-16.

Kityk, R., Vogel, M., Schlecht, R., Bukau, B., and Mayer, M.P. (2015). Pathways of allosteric regulation in Hsp70 chaperones. Nat. Commun. 6, 8308. https://doi. org/10.1038/ncomms9308.

Klaips, C.L., Jayaraj, G.G., and Hartl, F.U. (2018). Pathways of cellular proteostasis in aging and disease. J. Cell Biol. 217, 51-63. https://doi.org/10.1083/jcb.201709072.

Komander, D., and Rape, M. (2012). The ubiquitin code. Annu. Rev. Biochem. 81, 203-229. https://doi. org/10.1146/annurev-biochem-060310-170328.

Kondadi, A.K., Wang, S., Montagner, S., Kladt, N., Korwitz, A., Martinelli, P., Herholz, D., Baker, M.J., Schauss, A.C., Langer, T., et al. (2014). Loss of the m-AAA protease subunit AFG(3)L(2) causes mitochondrial transport defects and tau hyperphosphorylation. EMBO J 33, 1011-1026.

König, T., Tröder, S.E., Bakka, K., Korwitz, A., RichterDennerlein, R., Lampe, P.A., Patron, M., Mühlmeister, M., Guerrero-Castillo, S., Brandt, U., et al. (2016). The $\mathrm{m}$-AAA protease associated with neurodegeneration limits MCU activity in mitochondria. Mol. Cell 64, $148-162$.

Kowalski, L., Bragoszewski, P., Khmelinskii, A., Glow, E., Knop, M., and Chacinska, A. (2018). Determinants of the cytosolic turnover of mitochondrial intermembrane space proteins. BMC Biol. 16, 66. https://doi. org/10.1186/s12915-018-0536-1.

Kubo, Y., Tsunehiro, T., Nishikawa, S., Nakai, M., Ikeda, E., Toh-e, A., Morishima, N., Shibata, T., and Endo, T. (1999). Two distinct mechanisms operate in the reactivation of heat-denatured proteins by the 
mitochondrial Hsp70/Mdjlp/Ygelp chaperone system. J. Mol. Biol. 286, 447-464.

Latorre-Pellicer, A., Moreno-Loshuertos, R., LechugaVieco, A.V., Sánchez-Cabo, F., Torroja, C., Acín-Pérez, R., Calvo, E., Aix, E., González-Guerra, A., Logan, A., et al. (2016). Mitochondrial and nuclear DNA matching shapes metabolism and healthy ageing. Nature 535, 561-565.

Lazarou, M., Sliter, D.A., Kane, L.A., Sarraf, S.A., Wang, C., Burman, J.L., Sideris, D.P., Fogel, A.I., and Youle, R.J. (2015). The ubiquitin kinase PINK1 recruits autophagy receptors to induce mitophagy. Nature 524, 309-314. https://doi.org/10.1038/nature14893.

Lehmann, G., Ziv, T., Braten, O., Admon, A., Udasin, R.G., and Ciechanover, A. (2016). Ubiquitination of specific mitochondrial matrix proteins. Biochem. Biophys. Res. Commun. 475, 13-18. https://doi.org/10.1016/j. bbrc.2016.04.150.

Leonhard, K., Guiard, B., Pellecchia, G., Tzagoloff, A., Neupert, W., and Langer, T. (2000). Membrane protein degradation by AAA proteases in mitochondria: extraction of substrates from either membrane surface. Mol. Cell 5, 629-638.

Levytskyy, R.M., Bohovych, I., and Khalimonchuk, O. (2017). Metalloproteases of the Inner Mitochondrial Membrane. Biochemistry 56, 4737-4746. https://doi. org/10.1021/acs.biochem.7b00663.

Liu, Q. Krzewska, J., Liberek, K., and Craig, E.A. (2001). Mitochondrial Hsp70 Ssc1: role in protein folding. J. Biol. Chem. 276, 6112-6118. https://doi.org/10.1074/ jbc.M009519200.

Livnat-Levanon, N., Kevei, É., Kleifeld, O., Krutauz, D., Segref, A., Rinaldi, T., Erpapazoglou, Z., Cohen, M., Reis, N., Hoppe, T., et al. (2014). Reversible 26S proteasome disassembly upon mitochondrial stress. Cell Rep. 7, 1371-1380.

Lu, K., den Brave, F., and Jentsch, S. (2017). Receptor oligomerization guides pathway choice between proteasomal and autophagic degradation. Nat. Cell Biol. 19, 732-739. https://doi.org/10.1038/ncb3531.

Marshall, R.S., McLoughlin, F., and Vierstra, R.D. (2016). Autophagic Turnover of Inactive 26S Proteasomes in Yeast Is Directed by the Ubiquitin Receptor Cue5 and the Hsp42 Chaperone. Cell Rep. 16, 1717-1732.

Matheoud, D., Sugiura, A., Bellemare-Pelletier, A., Laplante, A., Rondeau, C., Chemali, M., Fazel, A., Bergeron, J.J., Trudeau, L.E., Burelle, Y., et al. (2016). Parkinson's disease-related proteins PINK1 and parkin repress mitochondrial antigen presentation. Cell 166, 314-327.

Matsuda, N., Sato, S., Shiba, K., Okatsu, K., Saisho, K., Gautier, C.A., Sou, Y.S., Saiki, S., Kawajiri, S., Sato, F., et al. (2010). PINK1 stabilized by mitochondrial depolarization recruits Parkin to damaged mitochondria and activates latent Parkin for mitophagy. J. Cell Biol. 189, 211-221. https://doi.org/10.1083/jcb.200910140.

McBride, H.M., Neuspiel, M., and Wasiak, S. (2006). Mitochondria: more than just a powerhouse. Curr. Biol. 16, R551-560.

McWilliams, T.G., and Muqit, M.M. (2017). PINK1 and Parkin: emerging themes in mitochondrial homeostasis. Curr. Opin. Cell Biol. 45, 83-91.

Miller, S.B., Mogk, A., and Bukau, B. (2015). Spatially organized aggregation of misfolded proteins as cellular stress defense strategy. J. Mol. Biol. 427, 1564-1574. https://doi.org/10.1016/j.jmb.2015.02.006.

Münch, C., and Harper, J.W. (2016). Mitochondrial unfolded protein response controls matrix pre-RNA processing and translation. Nature 534, 710-713.

Narendra, D., Kane, L.A., Hauser, D.N., Fearnley, I.M., and Youle, R.J. (2010). p62/SQSTM1 is required for Parkin-induced mitochondrial clustering but not mitophagy; VDAC1 is dispensable for both. Autophagy 6, 1090-1106.

Nargund, A.M., Pellegrino, M.W., Fiorese, C.J., Baker, B.M., and Haynes, C.M. (2012). Mitochondrial import efficiency of ATFS-1 regulates mitochondrial UPR activation. Science 337, 587-590. https://doi. org/10.1126/science.1223560.

Neutzner, A., Youle, R.J., and Karbowski, M. (2007). Outer mitochondrial membrane protein degradation by the proteasome. Novartis Found. Symp. 287, 4-14.

Nielson, J.R., Fredrickson, E.K., Waller, T.C., Rendón, O.Z., Schubert, H.L., Lin, Z., Hill, C.P., and Rutter, J. (2017). Sterol oxidation mediates stress-responsive Vms1 translocation to mitochondria. Mol. Cell 68, 673-685. e6.

Noguchi, M., and Kasahara, A. (2018). Mitochondrial dynamics coordinate cell differentiation. Biochem. Biophys. Res. Commun. 500, 59-64.

Nunnari, J., and Suomalainen, A. (2012). Mitochondria: in sickness and in health. Cell 148, 1145-1159. https:// doi.org/10.1016/j.cell.2012.02.035.

Nyström, T. (2013). Aging: filtering out bad mitochondria. Curr. Biol. 23, R1037-9. https://doi.org/10.1016/j. cub.2013.10.049.

Okreglak, V., and Walter, P. (2014). The conserved AAA-ATPase Msp1 confers organelle specificity to tail-anchored proteins. Proc. Natl. Acad. Sci. U.S.A. 111, 8019-8024. https://doi.org/10.1073/ pnas. 1405755111.

Opaliński, Ł., Becker, T., and Pfanner, N. (2014). Clearing tail-anchored proteins from mitochondria. Proc. Natl. Acad. Sci. U.S.A. 111, 7888-7889. https://doi. org/10.1073/pnas.1406864111.

Opaliński, Ł., Song, J., Priesnitz, C., Wenz, L.S., Oeljeklaus, S., Warscheid, B., Pfanner, N., and Becker, T. (2018). Recruitment of Cytosolic J-Proteins by TOM Receptors Promotes Mitochondrial Protein Biogenesis. Cell Rep. 25, 2036-2043.e5.

Osman, C., Wilmes, C., Tatsuta, T., and Langer, T. (2007). Prohibitins interact genetically with Atp23, a novel processing peptidase and chaperone for the F1Fo-ATP synthase. Mol. Biol. Cell 18, 627-635.

Pallafacchina, G., Zanin, S., and Rizzuto, R. (2018). Recent advances in the molecular mechanism of mitochondrial calcium uptake. F1000Res 7, F1000 Faculty Rev-1858. https://doi.org/10.12688/f1000research.15723.1.

Pareek, G., Thomas, R.E., and Pallanck, L.J. (2018). Loss of the Drosophila m-AAA mitochondrial protease paraplegin results in mitochondrial dysfunction, shortened lifespan, and neuronal and muscular degeneration. Cell Death Dis. 9, 304. https://doi. org/10.1038/s41419-018-0365-8.

Park, S.H., Kukushkin, Y., Gupta, R., Chen, T., Konagai, A., Hipp, M.S., Hayer-Hartl, M., and Hartl, F.U. (2013). PolyQ proteins interfere with nuclear degradation of 
cytosolic proteins by sequestering the Sis $1 \mathrm{p}$ chaperone. Cell 154, 134-145. https://doi.org/10.1016/j. cell.2013.06.003.

Patron, M., Sprenger, H.G., and Langer, T. (2018). m-AAA proteases, mitochondrial calcium homeostasis and neurodegeneration. Cell Res. 28, 296-306. https://doi. org/10.1038/cr.2018.17.

Paupe, V., and Prudent, J. (2018). New insights into the role of mitochondrial calcium homeostasis in cell migration. Biochem. Biophys. Res. Commun. 500, 75-86.

Pavlov, P.F., Hutter-Paier, B., Havas, D., Windisch, M., and Winblad, B. (2018). Development of GMP-1 a molecular chaperone network modulator protecting mitochondrial function and its assessment in fly and mice models of Alzheimer's disease. J. Cell. Mol. Med. $22,3464-3474$

Pfanner, N., Warscheid, B., and Wiedemann, N. (2019). Mitochondrial proteins: from biogenesis to functional networks. Nat. Rev. Mol. Cell Biol. [Epub ahead of print]. https://doi.org/10.1038/s41580-018-0092-0.

Pickles, S., Vigié, P., and Youle, R.J. (2018). Mitophagy and quality control mechanisms in mitochondrial maintenance. Curr. Biol. 28, R170-R185.

Pontano Vaites, L., and Harper, J.W. (2018). Protein aggregates caught stalling. Nature 555, 449-451. https://doi.org/10.1038/d41586-018-03000-2.

Priesnitz, C., and Becker, T. (2018). Pathways to balance mitochondrial translation and protein import. Genes Dev. 32, 1285-1296. https://doi.org/10.1101/ $\operatorname{gad} .316547 .118$.

Quirós, P.M., Langer, T., and López-Otín, C. (2015). New roles for mitochondrial proteases in health, ageing and disease. Nat. Rev. Mol. Cell Biol. 16, 345-359. https:// doi.org/10.1038/nrm3984.

Radke, S., Chander, H., Schäfer, P., Meiss, G., Krüger, R., Schulz, J.B., and Germain, D. (2008). Mitochondrial protein quality control by the proteasome involves ubiquitination and the protease Omi. J. Biol. Chem. 283, 12681-12685. https://doi.org/10.1074/jbc. C800036200.

Rape, M., Hoppe, T., Gorr, I., Kalocay, M., Richly, H., and Jentsch, S. (2001). Mobilization of processed, membrane-tethered SPT23 transcription factor by CDC48(UFD1/NPL4), a ubiquitin-selective chaperone. Cell 107, 667-677.

Reading, D.S., Hallberg, R.L., and Myers, A.M. (1989). Characterization of the yeast HSP60 gene coding for a mitochondrial assembly factor. Nature 337, 655-659. https://doi.org/10.1038/337655a0.

Ruan, L., Zhou, C., Jin, E., Kucharavy, A., Zhang, Y., Wen, Z., Florens, L., and Li, R. (2017). Cytosolic proteostasis through importing of misfolded proteins into mitochondria. Nature 543, 443-446. https://doi. org/10.1038/nature21695.

Ruan, L., Zhang, X., and Li, R. (2018). Recent insights into the cellular and molecular determinants of aging. J. Cell. Sci. 131 , jcs210831.

Rugarli, E.I., and Langer, T. (2012). Mitochondrial quality control: a matter of life and death for neurons. EMBO J. 31, 1336-1349. https://doi.org/10.1038/ emboj.2012.38.

Saarikangas, J., Caudron, F., Prasad, R., Moreno, D.F., Bolognesi, A., Aldea, M., and Barral, Y. (2017).
Compartmentalization of ER-bound chaperone confines protein deposit formation to the aging yeast cell. Curr. Biol. 27, 773-783.

Scarffe, L.A., Stevens, D.A., Dawson, V.L., and Dawson, T.M. (2014). Parkin and PINK1: much more than mitophagy. Trends Neurosci. 37, 315-324. https://doi. org/10.1016/j.tins.2014.03.004.

Schmitt, M., Neupert, W., and Langer, T. (1996). The molecular chaperone Hsp78 confers compartmentspecific thermotolerance to mitochondria. J. Cell Biol. 134, 1375-1386.

Schnell, D.J., and Hebert, D.N. (2003). Protein translocons: multifunctional mediators of protein translocation across membranes. Cell 112, 491-505.

Schorr, S., and van der Laan, M. (2018). Integrative functions of the mitochondrial contact site and cristae organizing system. Semin. Cell Dev. Biol. 76, 191-200.

Schulz, C., Schendzielorz, A., and Rehling, P. (2015). Unlocking the presequence import pathway. Trends Cell Biol. 25, 265-275. https://doi.org/10.1016/j. tcb.2014.12.001.

Shcheprova, Z., Baldi, S., Frei, S.B., Gonnet, G., and Barral, Y. (2008). A mechanism for asymmetric segregation of age during yeast budding. Nature 454, 728-734. https://doi.org/10.1038/nature07212.

Shen, P.S., Park, J., Qin, Y., Li, X., Parsawar, K., Larson, M.H., Cox, J., Cheng, Y., Lambowitz, A.M., Weissman, J.S., et al. (2015). Protein synthesis. Rqc2p and 60S ribosomal subunits mediate mRNA-independent elongation of nascent chains. Science 347, 75-78. https://doi. org/10.1126/science.1259724.

Shpilka, T., and Haynes, C.M. (2018). The mitochondrial UPR: mechanisms, physiological functions and implications in ageing. Nat. Rev. Mol. Cell Biol. 19, 109-120. https://doi.org/10.1038/nrm.2017.110.

Silva Ramos, E., Larsson, N.G., and Mourier, A. (2016). Bioenergetic roles of mitochondrial fusion. Biochim. Biophys. Acta 1857, 1277-1283.

Simões, T., Schuster, R., den Brave, F., and EscobarHenriques, M. (2018). Cdc48 regulates a deubiquitylase cascade critical for mitochondrial fusion. Elife 7, e30015. https://doi.org/10.7554/eLife.30015.

Sliter, D.A., Martinez, J., Hao, L., Chen, X., Sun, N., Fischer, T.D., Burman, J.L., Li, Y., Zhang, Z., Narendra, D.P., et al. (2018). Parkin and PINK1 mitigate STING-induced inflammation. Nature 561, 258-262. https://doi. org/10.1038/s41586-018-0448-9.

Sontag, E.M., Samant, R.S., and Frydman, J. (2017). Mechanisms and functions of spatial protein quality control. Annu. Rev. Biochem. 86, 97-122. https://doi. org/10.1146/annurev-biochem-060815-014616.

Sprenger, H.G., Wani, G., Hesseling, A., Konig, T., Patron, M., MacVicar, T., Ahola, S., Wai, T., Barth, E., Rugarli, E.I., et al. (2019). Loss of the mitochondrial i-AAA protease YME1L leads to ocular dysfunction and spinal axonopathy. EMBO Mol. Med. 11, pii: e9288. https:// doi.org/10.15252/emmm.201809288.

Stiburek, L., Cesnekova, J., Kostkova, O., Fornuskova, D., Vinsova, K., Wenchich, L., Houstek, J., and Zeman, J. (2012). YME1L controls the accumulation of respiratory chain subunits and is required for apoptotic resistance, cristae morphogenesis, and cell proliferation. Mol. Biol. 
Cell 23, 1010-1023. https://doi.org/10.1091/mbc. E11-08-0674.

Sugiura, A., McLelland, G.L., Fon, E.A., and McBride, H.M. (2014). A new pathway for mitochondrial quality control: mitochondrial-derived vesicles. EMBO J. 33, 2142-2156. https://doi.org/10.15252/ embj.201488104.

Suhm, T., Kaimal, J.M., Dawitz, H., Peselj, C., Masser, A.E., Hanzén, S., Ambrožič, M., Smialowska, A., Björck, M.L., Brzezinski, P., et al. (2018). Mitochondrial translation efficiency controls cytoplasmic protein homeostasis. Cell Metab. 27, 1309-1322.e6.

Tanaka, A., Cleland, M.M., Xu, S., Narendra, D.P., Suen, D.F., Karbowski, M., and Youle, R.J. (2010). Proteasome and p97 mediate mitophagy and degradation of mitofusins induced by Parkin. J. Cell Biol. 191, 1367-1380. https:// doi.org/10.1083/jcb.201007013.

Tatsuta, T., and Langer, T. (2017). Intramitochondrial phospholipid trafficking. Biochim. Biophys. Acta Mol. Cell Biol. Lipids 1862, 81-89.

Topf, U., Wrobel, L., and Chacinska, A. (2016). Chatty mitochondria: keeping balance in cellular protein homeostasis. Trends Cell Biol. 26, 577-586.

Tyedmers, J., Mogk, A., and Bukau, B. (2010). Cellular strategies for controlling protein aggregation. Nat. Rev. Mol. Cell Biol. 11, 777-788. https://doi.org/10.1038/ nrm2993.

van den Boom, J., and Meyer, H. (2018). VCP/p97mediated unfolding as a principle in protein homeostasis and signaling. Mol. Cell 69, 182-194.

Verma, R., Reichermeier, K.M., Burroughs, A.M., Oania, R.S., Reitsma, J.M., Aravind, L., and Deshaies, R.J. (2018). Vms1 and ANKZF1 peptidyl-tRNA hydrolases release nascent chains from stalled ribosomes. Nature 557, 446-451. https://doi.org/10.1038/s41586-0180022-5.

Vives-Bauza, C., Zhou, C., Huang, Y., Cui, M., de Vries, R.L., Kim, J., May, J., Tocilescu, M.A., Liu, W., Ko, H.S., et al. (2010). PINK1-dependent recruitment of Parkin to mitochondria in mitophagy. Proc. Natl. Acad. Sci. U.S.A. 107, 378-383. https://doi.org/10.1073/ pnas.0911187107.

Voos, W. (2013). Chaperone-protease networks in mitochondrial protein homeostasis. Biochim. Biophys. Acta 1833, 388-399. https://doi.org/10.1016/j. bbamcr.2012.06.005.

Voos, W., Jaworek, W., Wilkening, A., and Bruderek, M. (2016). Protein quality control at the mitochondrion. Essays Biochem. 60, 213-225.

Wagner, I., Arlt, H., van Dyck, L., Langer, T., and Neupert, W. (1994). Molecular chaperones cooperate with PIM1 protease in the degradation of misfolded proteins in mitochondria. EMBO J. 13, 5135-5145.

Wai, T., Saita, S., Nolte, H., Müller, S., König, T., Richter-Dennerlein, R., Sprenger, H.G., Madrenas, J., Mühlmeister, M., Brandt, U., et al. (2016). The membrane scaffold SLP2 anchors a proteolytic hub in mitochondria containing PARL and the i-AAA protease YME1L. EMBO Rep. 17, 1844-1856.

Wang, S., Jacquemyn, J., Murru, S., Martinelli, P., Barth, E., Langer, T., Niessen, C.M., and Rugarli, E.I. (2016). The Mitochondrial m-AAA protease prevents demyelination and hair greying. PLOS Genet. 12, e1006463. https:// doi.org/10.1371/journal.pgen.1006463.

Wang, X., and Chen, X.J. (2015). A cytosolic network suppressing mitochondria-mediated proteostatic stress and cell death. Nature 524, 481-484. https://doi. org/10.1038/nature 14859 .

Wang, X., Zuo, X., Kucejova, B., and Chen, X.J. (2008). Reduced cytosolic protein synthesis suppresses mitochondrial degeneration. Nat. Cell Biol. 10, 1090 1097.

Wasilewski, M., Chojnacka, K., and Chacinska, A. (2017). Protein trafficking at the crossroads to mitochondria. Biochim. Biophys. Acta Mol. Cell Res. 1864, 125-137.

Weidberg, H., and Amon, A. (2018). MitoCPR-A surveillance pathway that protects mitochondria in response to protein import stress. Science 360, eaan4146.

Whiteley, A.M., Prado, M.A., Peng, I., Abbas, A.R., Haley, B., Paulo, J.A., Reichelt, M., Katakam, A., Sagolla, M., Modrusan, Z., et al. (2017). Ubiquilin1 promotes antigen-receptor mediated proliferation by eliminating mislocalized mitochondrial proteins. Elife 6, e26435. https://doi.org/10.7554/eLife.26435.

Wiedemann, N., and Pfanner, N. (2017). Mitochondrial machineries for protein import and assembly. Annu. Rev. Biochem. 86, 685-714. https://doi.org/10.1146/ annurev-biochem-060815-014352.

Wohlever, M.L., Mateja, A., McGilvray, P.T., Day, K.J., and Keenan, R.J. (2017). Msp1 is a membrane protein dislocase for tail-anchored proteins. Mol. Cell 67, 194-202.e6.

Wrobel, L., Topf, U., Bragoszewski, P., Wiese, S., Sztolsztener, M.E., Oeljeklaus, S., Varabyova, A., Lirski, M., Chroscicki, P., Mroczek, S., et al. (2015). Mistargeted mitochondrial proteins activate a proteostatic response in the cytosol. Nature 524, 485-488. https://doi. org/10.1038/nature14951.

Wu, X., Li, L., and Jiang, H. (2016). Doal targets ubiquitinated substrates for mitochondria-associated degradation. J. Cell Biol. 213, 49-63. https://doi. org/10.1083/jcb.201510098.

Wu, X., Li, L., and Jiang, H. (2018). Mitochondrial innermembrane protease Ymel degrades outer-membrane proteins Tom22 and Om45. J. Cell Biol. 217, 139-149. https://doi.org/10.1083/jcb.201702125.

Xu, S., Peng, G., Wang, Y., Fang, S., and Karbowski, M. (2011). The AAA-ATPase p97 is essential for outer mitochondrial membrane protein turnover. Mol. Biol. Cell 22, 291-300. https://doi.org/10.1091/mbc.E1009-0748.

Yan, W., Schilke, B., Pfund, C., Walter, W., Kim, S., and Craig, E.A. (1998). Zuotin, a ribosome-associated DnaJ molecular chaperone. EMBO J. 17, 4809-4817. https:// doi.org/10.1093/emboj/17.16.4809.

Yonashiro, R., Tahara, E.B., Bengtson, M.H., Khokhrina, M., Lorenz, H., Chen, K.C., Kigoshi-Tansho, Y., Savas, J.N., Yates, J.R., Kay, S.A., et al. (2016). The Rqc2/ Tae2 subunit of the ribosome-associated quality control (RQC) complex marks ribosome-stalled nascent polypeptide chains for aggregation. Elife 5, e11794. https://doi.org/10.7554/eLife.11794.

Young, J.C., Hoogenraad, N.J., and Hartl, F.U. (2003). Molecular chaperones Hsp90 and Hsp70 deliver 
preproteins to the mitochondrial import receptor Tom70. Cell 112, 41-50.

Zanphorlin, L.M., Lima, T.B., Wong, M.J., Balbuena, T.S., Minetti, C.A., Remeta, D.P., Young, J.C., Barbosa, L.R., Gozzo, F.C., and Ramos, C.H. (2016). Heat shock protein $90 \mathrm{kDa}$ (Hsp90) has a second functional interaction site with the mitochondrial import receptor Tom70. J. Biol. Chem. 291, 18620-18631. https://doi. org/10.1074/jbc.M115.710137.

Zhang, H., Menzies, K.J., and Auwerx, J. (2018). The role of mitochondria in stem cell fate and aging. Development 145, dev143420.

Zhou, C., Slaughter, B.D., Unruh, J.R., Guo, F., Yu, Z., Mickey, K., Narkar, A., Ross, R.T., McClain, M., and Li,
R. (2014). Organelle-based aggregation and retention of damaged proteins in asymmetrically dividing cells. Cell 159, 530-542. https://doi.org/10.1016/j. cell.2014.09.026.

Zimorski, V., Ku, C., Martin, W.F., and Gould, S.B. (2014). Endosymbiotic theory for organelle origins. Curr. Opin. Microbiol. 22, 38-48. https://doi.org/10.1016/j. mib.2014.09.008.

Zurita Rendón, O., Fredrickson, E.K., Howard, C.J., Van Vranken, J., Fogarty, S., Tolley, N.D., Kalia, R., Osuna, B.A., Shen, P.S., Hill, C.P., et al. (2018). Vmslp is a release factor for the ribosome-associated quality control complex. Nat. Commun. 9, 2197. https://doi. org/10.1038/s41467-018-04564-3. 